\title{
ESTUDO SOBRE A OCORRENCIA DE AGUACEIROS E ESTIAGENS EM PRESIDENTE PRUDENTE, AVARÉ E ITAPEVA
}

\author{
ANTONIO ASSIZ DE CARVALHO FILHO
}

Orientador: Prof. Dr. VIVALDO FRANCISCO DA CRUZ

Dissertação apresentada à Escola Superior de Agricultura "Luiz de Queiroz", da Universidade de São Paulo, para obtenção do título de Mestre em Agronomia. Área de concentração: Estatística $\theta$ Experimentação Agronômica.

$P \mid R A C I C A B A$

Estado de São Paulo - Brasil

Dezembro, 1982 
ii.

A meus pais, Antonio Assiz

e Maria Aparecida,

e a meu filho Antonio Assiz de Carvalho Neto,

OFEREÇO.

A minha esposa Rosangela, DEDICO. 
Ao Prof. Dr. Vivaldo Francisco da Cruz, pelo estímulo durante o Cur so de Pós-Graduação, e pela sua orientação e amizade.

Ao Prof. Dr. Humberto de Canpos, por suas recomendaçoes e amizade.

Ao Prof. Dr. David Ariovaldo Banzatto, por suas sugestões -e pela revisão minuciosa que efetuou neste trabalho.

A Universidade Estadual Paulista, "Campus" de Presidente Prudente, em especial à pessoa do Dr. Roberto Pannain, por ter incentivado e dado apoio aos professores do I.P.E.A. para fazerem cursos de Pós-Graduação.

A Escola Superior de Agricultura "Luiz de Queiroz" (ESALQ/USP), a seus professores e Funcionários, pela amizade e apoio recebidos.

A Kikuko Abe, do Departamento de Aguas e Energia Elétrica do Esta do de São Paulo, por seu valioso auxílio na obtenção dos dados de precipitação pluviométrica utilizados no presente trabalho.

Ass alunas Vilma Lucia Macagnan e Tânia Maria Fresca, do Curso de Geografia, pela colaboração no levantamento dos dados.

Às Srtas. Maria Izalina Ferreira Alves e Rosa Maria Alves, pela a tenção e apoio dados durante o Curso.

A Srta. Carmen Lucia Mazzarotto Negrini, do I.P.E.A. pela datilo grafia da revisão final deste trabalho. 
1. INTRODUÇÃO $\ldots \ldots \ldots \ldots \ldots \ldots \ldots \ldots \ldots \ldots \ldots \ldots \ldots \ldots \ldots \ldots \ldots \ldots \ldots \ldots$

2. REVISÃO DE LITERATURA $\ldots \ldots \ldots \ldots \ldots \ldots \ldots \ldots \ldots \ldots \ldots \ldots \ldots \ldots \ldots \ldots \ldots$

3. MATERIAL E METODOS $\ldots \ldots \ldots \ldots \ldots \ldots \ldots \ldots \ldots \ldots \ldots \ldots$

3.1 - Dados Utilizados $\ldots \ldots \ldots \ldots \ldots \ldots \ldots \ldots \ldots \ldots \ldots$

3.2 - Metodologia $\ldots \ldots \ldots \ldots \ldots \ldots \ldots \ldots \ldots \ldots \ldots \ldots \ldots . \ldots \ldots$

3.2 .1 - A distribuição de Gumbel $\ldots \ldots \ldots \ldots \ldots \ldots 21$

3.2.1.1 - A obtenção dos parâmetros a e u .. 21

3.2.1.2 - A estimativa dos parâmetros $\alpha$ e u 25

3.2 .2 - A distribuição de Poisson $\ldots \ldots \ldots \ldots \ldots \ldots$

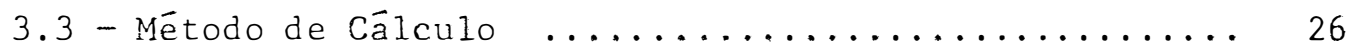

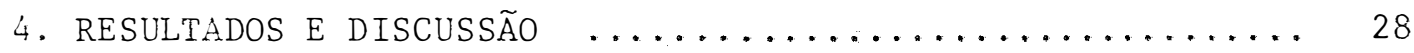

4.1 - Sugestões Para Pesquisas Posteriores .......... 70

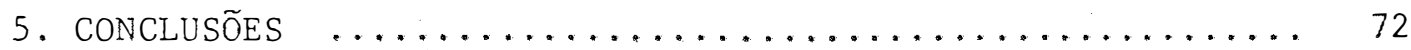

6. Literatura CITADA $\ldots \ldots \ldots \ldots \ldots \ldots \ldots \ldots \ldots \ldots \ldots \ldots \ldots$ 


\section{LISTA DE TABELAS}

TABELA

1 Ordem cronológica da duração (em nümero de dias secos consecutivos) das estiagens mais longas e das precipi tações māximas (em nm) no período de um dia, observadas na cidade de Presidente Prudente, SP, no período

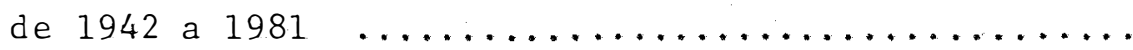

2 Ordem cronolôgica do número de ocorrências anuais de estiagens de duração não inferior a 30 dias secos con secutivos e de aguaceiros de altura não inferior a 50 mm de precipitação diāria, observadasna cidade de Pre sidente Prudente, SP, no período de 1942 a 1981 ....

3 Ordem cronológica da duração (em número de dias secos consecutivos) das estiagens mais longas e das precipi tações máximas (em mm) no pe ríodo de um dia, observa das na cidade de Avaré, SP, nos anos de 1942 a 1981.

4 Ordem cronolögica do número de ocorrências anuais de estiagens de duração não inferior a 30 dias secos con secutivos e de aguaceiros de altura não inferior a 50 mm de precipitação diāria, observadas na cidade de Avaré, SP, no período de 1942 a 1981 .............

5 Ordem cronológica da duração (em nümero de dias secos consecutivos) das estiagens mais longas e das precipi tações máximas (em mm) no período de um dia, observa das na cidade de Itapeva, SP, nos anos de 1942 a 1981 
6 Ordem cronológica do número de ocorrências anuais de estiagens de duração não inferior a 30 dias secos con secutivos e de aguaceiros de altura não inferior a 50 $\mathrm{mm}$, observadas na cidade de Itapeva, SP, no período de 1942 a 1981

7 Dados originais, referentes a Presidente Prudente, SP., no ano de 1958, para precipitação máxima e estiagem

8 Dados originais, referentes a Presidente Prudente,SP., no ano de 1958, para ocorrências de aguaceiros $e$ es tiagens

9 Estruturação do teste de $\chi^{2}$ para os dados de estiagens referentes à cidade de Presidente Prudente, SP. F(x): Função de Distribuição Normal

10 Estruturação do teste de $\chi^{2}$ para os dados de estiagens referentes à cidade de Presidente Prudente, SP. F(x): Função de Distribuição Lognormal

11 Estimativas da duração máxima provável da estiagem mais longa do ano, em número de dias secos consecutivos e a probabilidade dessas estimativas não serem u1 trapassadas, para a cidade de Presidente Prudente, SP

12 Estruturação do teste de $\chi^{2}$ para os dados de estiagens referentes à cidade de Presidente Prudente, SP, F(x): Função de Distribuição de Gumbel $\ldots \ldots \ldots \ldots \ldots \ldots$ 
vii.

TABELA

Pàg.

13 Ocorrência de estiagens de duração não inferior a 30 dias secos consecutivos, durante 40 anos (1942, 1981)

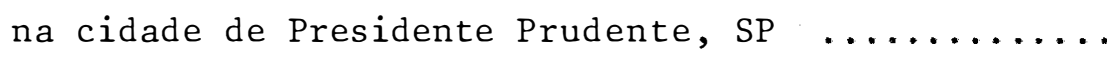

14 Estruturação do teste de $x^{2}$ para os dados de precipitação pluviométrica referentes à cidade de Presidente Prudente, SP. F(x): Função de Distribuição Normal ..

15 Estruturação do teste de $x^{2}$ para os dados de precipitação pluviométrica referentes à cidade de Presidente Prudente, SP. $F(x)$ : Função de Distribuição Lognormal

16 Estimativas da precipitação máxima provāvel no período de um dia, e a probabilidade dessas estimativas não serem ultrapassadas, para a cidade de Presidente Pru-

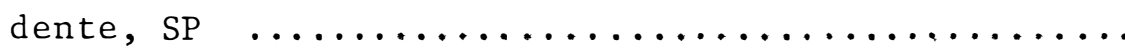

17 Estruturação do teste de $x^{2}$ para os dados de precipitação pluviométrica referentes à cidade de Presidente Prudente, SP, $F(x)$ : Função de Distribuição de Gumbel

18 Ocorrência de aguaceiros de altura não inferior a 50 Im durante 40 anos $(1942,1981)$, na cidade de Presidente Prudente, $\mathrm{sP} \quad \ldots \ldots \ldots \ldots \ldots \ldots \ldots \ldots \ldots$

19 Estruturação do teste de $x^{2}$ aos dados de estiagens re ferentes à cidade de Avaré, SP. F(x): Função de Distribuição Normal $\ldots \ldots \ldots \ldots \ldots \ldots \ldots \ldots$ 
viii.

TABELA

Pāg.

20 Estruturação do teste de $x^{2}$ aos dados de estiagens re ferentes à cidade de Avaré, SP. F(x): Função de Dis-

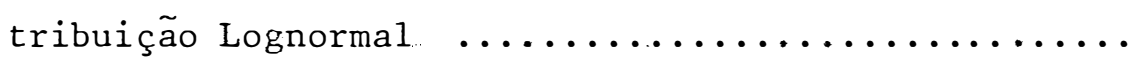

21 Estimativas da duração máxima provável da estiagem mais longa do ano, em número de dias secos consecutivos, e a probabilidade dessas estimativas não serem ultrapassadas, para a cidade de Avaré, SP $\ldots . . . \ldots$

22 Estruturação do teste de $\chi^{2}$ para os dados de estiagens referentes à cidade de Avaré, SP. $F(x)$ : Função de dis tribuição de Gumbel $\ldots \ldots \ldots \ldots \ldots \ldots \ldots \ldots \ldots \ldots$

23 Ocorrência de estiagens de duração não inferior a 30 dias secos consecutivos, durante 40 anos (1942, 1981), na cidade de Avaré, SP $\ldots \ldots \ldots \ldots \ldots \ldots \ldots \ldots$

24 Estruturação do teste de $\chi^{2}$ aos dados de precipitação pluviométrica referentes à cidade de Avaré, SP. F(x): Função de Distribuição Normal

25 Estruturação do teste de $\chi^{2}$ aos dados de precipitação pluviométrica referentes à cidade de Avaré, SP. F(x): Função de Distribuição Lognormal $\ldots \ldots \ldots \ldots \ldots \ldots \ldots$

26 Estimativas de precipitação máxima provāvel no período de um dia, e a probabilidade dessas estimativas não serem ultrapassadas, para a cidade de Avaré, SP ... 
27 Estruturação do teste de $x^{2}$ aos dados de precipitação pluviométrica referentes à cidade de Avaré, SP. F(x): Função de Distribuição de Gumbel $\ldots \ldots \ldots \ldots \ldots \ldots$

28 Ocorrência de aguaceiros de altura não inferior a 50 mm durante 40 anos $(1942,1981)$, na cidade de Avaré, SP

29. Estruturação do teste de $x^{2}$ aos dados de estiagens re ferentes à cidade de Itapeva, SP. F(x): Função de Dis tribuição Normal $\ldots \ldots \ldots \ldots \ldots \ldots \ldots \ldots \ldots$

30 Estruturação do teste de $\chi^{2}$ aos dados de estiagens re ferentes à cidade de Itapeva, SP. F(x): Função de Dis tribuição Lognormal $\ldots \ldots \ldots \ldots \ldots \ldots \ldots \ldots \ldots$

31 Estimativas da duração máxima provável da estiagem mais longa do ano, em número de dias secos consecutivos, e a probabilidade dessas estimativas não serem ultrapassadas, para a cidade de Itapeva, SP ......

32 Estruturação do teste de $x^{2}$ aos dados de estiagens re ferentes à cidade de Itapeva, SP. F(x): Função de Dis tribuição de Gumbel $\ldots \ldots \ldots \ldots \ldots \ldots \ldots \ldots \ldots$

33 Ocorrência de estiagens de duração não inferior a 30 dias consecutivos durante 40 anos (1942, 1981), para a cidade de Itapeva, $\mathrm{sP} \ldots \ldots \ldots \ldots \ldots \ldots \ldots \ldots \ldots$ 
34 Estruturação do teste de $x^{2}$ aos dados de precipitação pluviomêtrica referentes à cidade de Itapeva, SP.F(x): Função de Distribuição Normal $\ldots \ldots \ldots \ldots \ldots \ldots \ldots . \ldots 6$

35 Estruturação do teste de $x^{2}$ aos dados de precipitação pluviométrica referentes à cidade de Itapeva,SP. F(x): Função de Distribuição Lognormal $\ldots \ldots \ldots \ldots \ldots \ldots$

36 Estimativas da precipitação māxima provável no período de um dia, e a probabilidade dessas estimativas não serem ultrapassadas, para a cidade de Itapeva, SP ..

37 Estruturação do teste de $x^{2}$ aos dados de precipitação pluviométrica referentes à cidade de Itapeva,SP. F(x):

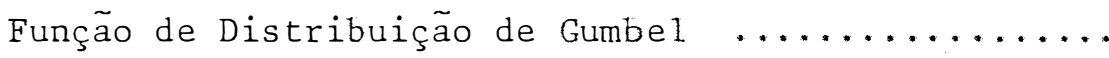

38 Ocorrência de aguaceiros de altura não inferior a 50 mm durante 40 anos $(1942,1981)$, na cidade de Itapeva, SP 


\section{ESTUDO SOBRE A OCORRENCIA DE AGUACEIROS E ESTIAGENS}

\section{EM PRESIDENTE PRUDENTE, AVARE E ITAPEVA}

Candidato: Antonio Assiz de Carvalho Filho

Orientador: Prof. Dr. Vivaldo Francisco da Cruz

\section{RES U M O}

Com o fim de estudar:

a) a duração máxima provāvel, em número de dias secos consecutivos, da estiagem mais longa do ano;

b) a precipitação pluviométrica máxima provável no período de um dia, do ano;

c) a probabilidade de ocorrência anual de aguaceiros de altura não inferior a $50 \mathrm{~mm}$ diārios;

d) a probabilidade de ocorrência anual de estiagens de duração não inferior a 30 dias secos consecutivos;

tomaram-se, então, os dados de precipitação pluviométrica referentes aos anos de 1942 a 1981, inclusive, de Presidente Prudente, Avą ré e Itapeva, Estado de São Paulo. 
As estimativas da duração máxima provável da estiagem mais longa do ano e da precipitação pluviométrica máxima provável no período de um dia, do ano, foram feitas utilizando-se a função de distribuição de valores extremos proposta por Gumbel; e as estimativas das probabilidades de ocorrências de estiagens de duração não inferior a 30 dias secos consecutivos e de aguaceiros de a 1 tura igual ou superior a $50 \mathrm{~mm}$ diārios, foram feitas utilizando-se a função de distribuição de Poisson.

As seguintes conclusões foram tiradas:

1) A estimativa da duração máxima provāvel da estiagem mais 1 on ga do ano, com probabilidade de 5\% dessa estimativa ser u1trapassada, para a cidade de Presidente Prudente è de 78 dias secos consecutivos, para a cidade de Avaré é de 74 dias e para a cidade de Itapeva é de 62 dias respectivamente.

2) Durante o ano, a probabilidade de que ocorra no máximo uma estiagem de duração não inferior a 30 dias secos consecutivos é estimada em $71,73 \%$ para a cidade de Presidente Pruden te, $83,54 \%$ para a cidade de Avaré e $90,98 \%$ para a cidade de Itapeva.

3) Durante o ano, a precipitação máxima provável no período de um dia é estimada em 10.6,5: mm para a cidade de Itapeva. 
xiii.

4) A probabilidade de ocorrer no ano pelo menos um aguaceiro de altura não inferior a $50 \mathrm{~mm}$ diārïos é estimada em $96,83 \%$ pa a ra a cidade dé Avaré.

5) A função do tipo exponencial indicada para o estudo de dados de estiagem e precipitação pluviomética (máximas registradas de cada ano) é a função lognormal. 
xiv.

\section{STUDY ON OCCURRENCE OF HEAVY DOWNPOUR AND DROUGHT} FOR PRESIDENTE PRUDENTE, AVARE AND ITAPEVA

Candidate: Antonio Assiz de Carvalho Filho

Adviser: Prof. Dr. Vivaldo Francisco da Cruz

\section{$S \cup M M A R Y$}

In order to study:

a) the maximum probable duration of drought (dry days consecutive) of the year;

b) the maximum probable rainfall with one day period of the year;

c) the annual probabilityoccurrence of heavy downpour of a height greater than $50 \mathrm{~mm}$;

d) the annual probability occurrence of drought of height greater than 30 dry days consecutive;

to this, the data of rain precipitation for Presidente Prudente, Avarē and Itapeva, São Paulo State, were taken. 
The annual frequence of drought and heavy downpours were studied by a Poisson's theory, and the maximum probable rainfall and drought were studied by the extreme values distribution proposed by Gumbel.

According to the data, the following conclusions were drawn:

1) The estimative of the maximum probable duration of drought of the year where 78 dry days consecutive for Presidente Pru dente, 74 dry days consecutive for Avare and 62 dry days con secutive for Itapeva.

2) In the year, the probability of occurrence of no more than one drought of height greater than 30 dry days consecutive were 71,73\% for Presidente Prudente, 83,54\% for Avare and $90,98 \%$ for Itapeva.

3) The maximum probable rainfall with one day period, of the year to Itapeva were $106,5 \mathrm{~mm}$.

4) In the year, the probability of occurrence of at least one heavy downpour of height greater than $50 \mathrm{~mm}$ were $96,83 \%$ for Avare.

5) The best distribution of exponential type for the data concerning to Presidente Prudente, Avare and Itapeva (rain data and drought data) were the lognormal distribution. 
1.

1. INTRODUÇÃO

o conhecimento antecipado da duração máxima provāvel da estiagem mais longa do ano e da precipitação pluviométrica máxima provável (período de um dia) do ano, assim como da probabilidade anual de ocorrência de aguaceiros de altura $h>50$ mm e de estiagens de duração não inferior a 30 dias secos consecutivos, é de importân cia considerável aos agricultores e àqueles que exercem suas atividades junto a eles, proporcionando dados que possibilitam planejamentos mais precisos, tais como nos projetos de irrigação e abastecimento de água, em que há necessidade de se conhecerem as grandezas das estiagens e das precipitações que adviriam.

Em estudos sobre precipitação máxima provāvel, vārios autores têm se utilizado da função estabelecida por Gumbel para a análise de dados extremos; e em estudos sobre frequência de ocorrên 
cia de aguaceiros de altura $h \geq 50 \mathrm{~mm}$, alguns autores têm se utilizado da função de distribuição de Poisson.

Já foram feitos estudos sobre a estimativa de precipitações máximas prováveis para o Estado de São Paulo, e também sobre a ocorrência de aguaceiros de altura excepcional para uma cidade desse mesmo Estado, mas nada se encontrou sobre estimativas da duração máxima provâvel da estiagem mais longa do ano, utilizando-se a função de distribuição de valores extremos proposta por Gumbel, e da frequência anual de ocorrência de estiagens de duração não inferior a 30 dias secos consecútivos, utilizando-se a distribuição de Poisson.

Pelo exposto, o presente trabalho tem :por objetivo estimar:

1) A duração máxima provável, em número de dias secos consecutivos, da estiagem mais longa do ano;

2) a probabilidade anual de ocorrência de estiagens de duração não inferior a 30 dias secos consecutivos;

3) a precipitação pluviométrica máxima provável (período de um dia) do ano;

4) a probabilidade anual de ocorrência de aguaceiros de altura $\mathrm{h} \geq 50 \mathrm{~mm}$.

Um dia seco è definido como um dia com menos de $1 \mathrm{~mm}$ de chuva. 
Optou-se em coletar os dados para o presente estudo nas cidades de Presidente Prudente, Avaré e Itapeva, por possuirem séries com mais de 30 anos de observação. 


\section{REVISAOO DE LITERATURA}

As propriedades estatísticas dos valores extremos de pendem principalmente das propriedades da função de distribuição inicial para valores grandes (extremos superiores) ou pequenos (extremos inferiores) da variável de interesse.

Uma função de distribuição estabelecida exclusivamen te para a análise de valores extremos com base na distribuição tipo I de Fisher e Tipett, foi demonstrada em teoria desenvolvida por GUM BEL (1941).

De acordo com Hidrometeorologistas, Hidrólogos e outros interessados na frequência de valores extremos de grandezas me teorológicas, climatológicas ou hidrológicas, verifica-se que a dis tribuição desses valores extremos aproxima-se satisfatoriamente da distribuição tipo I de Fisher e Tipett, conhecida também como dis tribuição de Gumbel (OCCHIPINTI e SANTOS, 1965). 
Segundo GARCEZ (1967), Gumbel, através da teoria dos valores extremos, forneceu um método para previsões de enchentes, onde os parâmetros são estimados a partir de amostras constituídas pelas maiores vazões diárias de cada ano, presumindo-se que os dados da amostra têm distribuição do tipo exponencial, o que é confir mado por CHOW (1964) e BANZATTO (1973).

Como a medida de dados pluviométricos é, quase sempre, mais fácil que a das vazões, com frequência faz-se o estudo das vazões máximas de modo indireto, através de dados pluviométricos (GARCEZ, 1967).

$$
\text { OCCHIPINTI e SANTOS (1965), SILVA e ASSIS (1969), }
$$

e KRISHNAM e KUSHWAHA (1978), em seus estudos, não veri ficaram se os dados de precipitação pluviométrica ajustam-se a algu ma função de distribuição do tipo exponencial, assim como não mencionam que tal procedimento seja desnecessārio.

GARCEZ (1967), e VILLELA e MATTOS (1980) afirmam que séries longas de alturas pluviométricas anuais (mais que 30 anos) se adaptam bem à Lei de Gauss, desde que os elementos da série sejam considerados sem ordem de sucessão.

Na bibliografia disponível, nada se encontrou no que se refere ao ajuste de séries de alturas pluviométricas (máximas re gistradas durante o ano no período de um dia) e de séries de estia gens mais longas do ano, para diversos anos em estudo, a alguma dis tribuição do tipo exponencial. 
Observa-se, entretanto, que a distribuição de Gumbel é considerada atualmente uma das mais usuais em estudos de estimati vas de precipitações máximas prováveis, mas pouco se encontra sobre a aplicação da mesma em estudos de estimativas da duração máxima pro vável da estiagem mais longa do ano.

Aplicações da teoria dos valores extremos, desenvolvida por Gumbel para estimativa das precipitações máximas prováveis, podem ser observadas em estudos realizados por OCCHIPINTI e SANTOS (1965) para a cidade de São Paulo, por BANZATTO (1973), para o Esta do de São Paulo, e por KRISHNAM e KUSHWAHA (1978) para a India. Para a estimativa da duração das estiagens mais longas do ano no Triângu gulo Mineiro, SILVA e ASSIS (1979) afirmam teram utilizado a função de distribuição de Gumbel, mas não apresentam nada alēm da estimati va da duração do período seco mais longo do ano.

SCOTON e CRUZ (1966), através da distribuição de Pois son, calcularam a probabilidade de ocorrência de aguaceiros de altu ra excepcional ( $\mathrm{n} \geq 50 \mathrm{~mm}$ ) em Piracicaba. Inspirando-se nesse estudo, pensou-se que também a probabilidade de ocorrência de estiagens poderiam ser estudadas por esta distribuição.

Segundo HOEL et alii (1978), sabe-se de experiência que muitos fenômenos aleatôrios que envolvem contagem seguem aproxi madamente a distribuição de Poisson.

Segundo GNEDENKO (1978), com relação a um processo de Poisson, pressupõe-se que: 
1. o processo seja estacionário;

2. haja ausência de efeito posterior;

3. haja ordinariedade.

De acordo com BHAT (1972), se $X(t)$ é o nümero de even tos ocorridos no intervalo de tempo $(0, t]$, obedecendo as pressuposições 1, 2, 3; demonstra-se que $X(t)$ tem distribuição de Poisson com mêdia $\lambda t$, e o processo de ocorrência $\{x(t)\}$ é denominado proces so de Poisson.

As ocorrências de aguaceiros $(\mathrm{h} \geq 50 \mathrm{~mm}$ ) e estiagens de duração não inferior a 30 dias secos consecutivos são fenômenos pouco frequentes nesta região. Pode-se, pois, considerar o número de ocorrências durante o ano desses dois fenômenos como uma variāvel casual, que pode ser estudada através da distribuição de Poisson. 
8.

\section{MATERIAL E METODOS}

De acordo com o Departamento de Āguas e Energia Elétrica do Estado de São Paulo, constitui a $4^{\text {a }}$. Zona Hidrogrä́fica deste Estado a bacia do Rio Paranapanema, a montante de sua confluência com o rio Itararē, a vertente leste deste $\bar{u} 1$ timo, a vertente Nor te do rio Paranapanema, a jusante do Itararé, a bacia do rio Santo Anastācio e o Paranapanema, drenando diretamente o rio Paranā. Aärea total da 4 a. zona ể de aproximadamente $23 \%$ da ārea do Estado de São Paulo,

Os dados utilizados no presente estudo: foram obtidos dos boletins pluviométricos publicados pelo Departamento de Āguas e Energia Elétrica da Secretaria de Serviços e Obras Pưblicas do Esta do de São Paulo. 


\section{1 - Dados Utilizados}

Dos postos instalados na $4^{\text {a }}$ Zona Hidrogrä́fica, apenas os de Presidente Prudente, Avaré e Itapeva possuem séries com mais de 30 anos de registro.

Na Figura 1 tem-se o mapa da $4^{\text {a }}$ Zona Hidrogrä́rica e as cidades de Presidente Prudente, Avaré e Itapeva.

Os dados obtidos dessas cidades encontram-se nas Tabelas $1,2,3,4,5$ e 6 .

Os nümeros das Tabelas 1, 3 e 5 indicam:

Estiagem: quantos dias secos consecutivos teve a estiagem mais longa verificada naquele ano.

Precipitação: a precipitação mäxima em milímetros (no período de um dia) registrada no ano.

Na Tabela $J$ mostra-se como os dados para essas tabelas foram obtidos.

Os nümeros das Tabelas 2, 4 e 6 indicam:

Estiagem: quantas estiagens de duração não inferior a 30 dias secos consecutivos ocorreram naquele ano.

Aguaceiro: quantos aguaceiros de altura excepcional ( $\mathrm{h} \geq 50 \mathrm{~mm}$ ) ocorreram em cada ano.

Na Tabela 8 mostra-se como os dados para essas tabelas foram obtidos. 


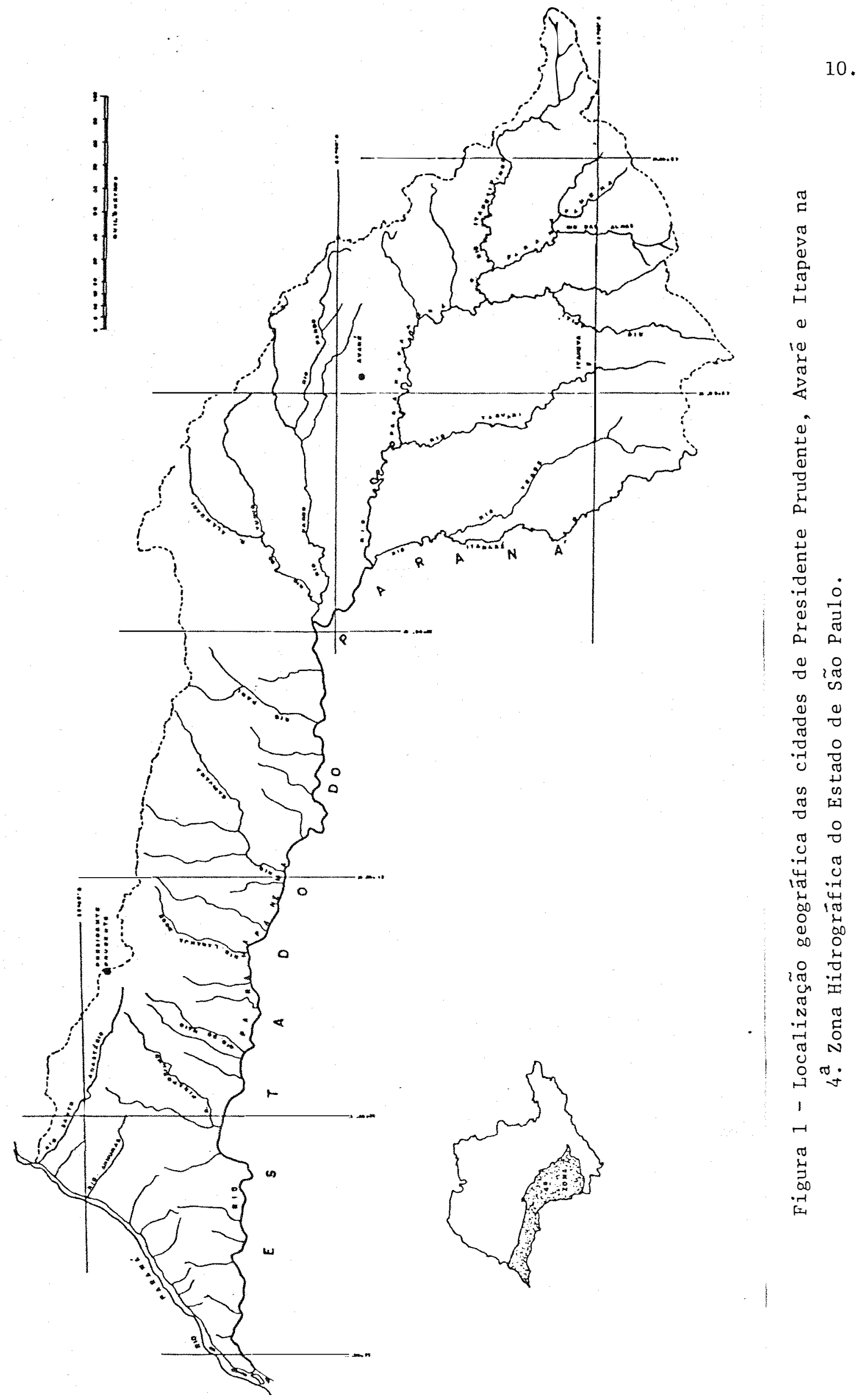


Tabela 1 - Ordem cronológica da duração (em nümero de dias secos con secutivos) das estiagens mais longas e das precipitações (em $\mathrm{mm}$ ) mäximas no período de um dia, observadas na cida de de Presidente Prudente, SP, no período de 1942 a 1981.

\begin{tabular}{|c|c|c|c|c|c|}
\hline ANO & Estiagem & Precipitação & ANO & Estiagem & Precipitação \\
\hline 1942 & 25 & 75,0 & 1962 & 63 & 60,1 \\
\hline 1943 & 82 & 51,5 & 1963 & 64 & 81,1 \\
\hline 1944 & 59 & 54,3 & 1964 & 25 & 246,5 \\
\hline 1945 & 36 & 72,0 & 1965 & 25 & 80,0 \\
\hline 1946 & 63 & 80,0 & 1966 & 31 & 59,2 \\
\hline 1947 & 46 & 90,0 & 1967 & 61 & 106,7 \\
\hline 1948 & 46 & 102,5 & 1968 & 29 & 140,3 \\
\hline 1949 & 70 & 40,0 & 1969 & 43 & 66,6 \\
\hline 1950 & 58 & 77,1 & 1970 & 43 & 103,0 \\
\hline 1951 & 46 & 70,0 & 1971 & 37 & 108,0 \\
\hline 1952 & 70 & 78,0 & 1972 & 23 & 89,4 \\
\hline 1953 & 36 & 53,0 & 1973 & 19 & 82,0 \\
\hline 1954 & 85 & 152,0 & 1974 & 27 & 113,0 \\
\hline 1955 & 40 & 83,0 & 1975 & 66 & 95,8 \\
\hline 1956 & 36 & 65,5 & 1976 & 25 & 70,0 \\
\hline 1957 & 24 & 111,5 & 1977 & 22 & 85,0 \\
\hline 1958 & 33 & 66,2 & 1978 & 45 & 89,1 \\
\hline 1959 & 54 & 50,9 & 1979 & 23 & 50,7 \\
\hline 1960 & 34 & 79,2 & 1980 & 28 & 181,4 \\
\hline 1961 & 70 & 80,5 & 1981 & 46 & 76,5 \\
\hline
\end{tabular}


Tabela 2 - Ordem cronológica do nümero de ocorrências anuais de estiagens de duração não inferior a 30 dias secos consecutivos e de aguaceiros de altura não inferior a $50 \mathrm{~mm}$ de precipitação diāria, observadas na cidade de Presidente Prudente, SP, no período de 1942 a 1981.

\begin{tabular}{|c|c|c|c|c|c|}
\hline ANO & Estiagem & Aguaceiro & ANO & Estiagem & Aguaceiro \\
\hline 1942 & 0 & 4 & 1962 & 1 & 3 \\
\hline 1943 & 2 & 1 & 1963 & 2 & 3 \\
\hline 1944 & 1 & 1 & 1964 & 0 & 3 \\
\hline 1945 & 1 & 2 & 1965 & 0 & 5 \\
\hline 1946 & 1 & 1 & 1966 & 1 & 0 \\
\hline 1947 & 1 & 5 & 1967 & 2 & 3 \\
\hline 1948 & 2 & 2 & 1968 & 0 & 4 \\
\hline 1949 & 1 & 0 & 1969 & 1 & 3 \\
\hline 1950 & 2 & 2 & 1970 & 1 & 3 \\
\hline 1951 & 2 & 5 & 1971 & 1 & 6 \\
\hline 1952 & 2 & 3 & 1972 & 0 & 6 \\
\hline 1953 & 1 & 1 & 1973 & 0 & 6 \\
\hline 1954 & 1 & 4 & 1974 & 0 & 7 \\
\hline 1955 & 1 & 1 & 1975 & 2 & 3 \\
\hline 1956 & 1 & 5 & 1976 & 0 & 3 \\
\hline 1957 & 0 & 5 & 1977 & 0 & 4 \\
\hline 1958 & 1 & 3 & 1978 & 3 & 1 \\
\hline 1959 & 2 & 1 & 1979 & 0 & 1 \\
\hline 19.60 & 1 & 5 & 1980 & 0 & 3 \\
\hline 1961 & 2 & 5 & 1981 & 3 & 1 \\
\hline
\end{tabular}


Tabela 3 - Ordem cronológica da duração (em número de dias secos con secutivos) das estiagens mais longes e das precipitações máximas no período de um dia, observadas na cidade de Avarê, SP, nos anos de 1942 a 1981 .

\begin{tabular}{|c|c|c|c|c|c|}
\hline ANO & Estiagem & Precipitação & ANO & Estiagem & Precipitação \\
\hline 1942 & 47 & 58,6 & 1962 & 27 & 89,2 \\
\hline 1943 & 76 & 69,8 & 1963 & 99 & 81,0 \\
\hline 1944 & 58 & 63,4 & 1964 & 27 & 116,5 \\
\hline 1945 & 34 & 80,4 & 1965 & 26 & 89,3 \\
\hline 1946 & 30 & 69,8 & 1966 & 31 & 97,7 \\
\hline 1947 & 19 & 77,0 & 1967 & 46 & 68,1 \\
\hline 1948 & 37 & 83,7 & 1968 & 22 & 47,4 \\
\hline 1949 & 75 & 52,0 & 1969 & 28 & 44,0 \\
\hline 1950 & 61 & 80,7 & 1970 & 30 & 93,7 \\
\hline 1951 & 27 & 70,5 & 1971 & 26 & 63,3 \\
\hline 1952 & 57 & 87,6 & 1972 & 18 & 89,9 \\
\hline 1953 & 30 & 74,9 & 1973 & 16 & 66,7 \\
\hline 1954 & 58 & 69,8 & 1974 & 46 & 63,0 \\
\hline 1955 & 43 & 135,4 & 1975 & 68 & 59,5 \\
\hline 1956 & 24 & 83,7 & 1976 & 21 & 106,5 \\
\hline 1957 & 17 & 64,1 & 1977 & 35 & 167,2 \\
\hline 1958 & 29 & 63,0 & 1978 & 32 & 69,9 \\
\hline 1.959 & 28 & 66,0 & 19.79 & 37 & 56,2 \\
\hline 1960 & 44 & 88,8 & 1980 & $2 . \bar{i}$ & 86,4 \\
\hline 1961 & 64 & 80,5 & 1981 & 20 & 62,4 \\
\hline
\end{tabular}


Tabela 4 - Ordem cronológica do numero de ocorrências anuais de estiagens de duraçãc não inferior a 30 dias secos consecutivos e de aguaceiros de altura não inferior a $50 \mathrm{~mm}$ de precipitação diāria, observadas na cidade de Avaré, SP, no períudo de 1942 a 1981.

\begin{tabular}{|c|c|c|c|c|c|}
\hline ANO & Estiagem & Aguaceiro & ANO & Estiagem & Aguaceiro \\
\hline 1942 & 1 & 1 & 1962 & 0 & 3 \\
\hline 1943 & 1 & 2 & 1963 & 1 & 4 \\
\hline 1944 & 1 & 3 & 1964 & 0 & 3 \\
\hline 1945 & 2 & 3 & 1965 & 0 & 9 \\
\hline 1946 & 1 & 3 & 1966 & 1 & 4 \\
\hline 1947 & 0 & 6 & 1967 & 2 & 4 \\
\hline 1948 & 2 & 2 & 1968 & 0 & 0 \\
\hline 1949 & 1 & 2 & 1969 & 0 & 0 \\
\hline 1950 & 2 & 2 & 1970 & 1 & 3 \\
\hline 1951 & 0 & 3 & 1971 & 0 & 2 \\
\hline 1952 & 3 & 6 & 1972 & 0 & 6 \\
\hline 1953 & 1 & 1 & 1973 & 0 & 8 \\
\hline 1954 & 1 & 2 & 1974 & 1 & 3 \\
\hline 1955 & 1 & 5 & 1975 & 1 & 4 \\
\hline 1956 & 0 & 5 & 1976 & 0 & 5 \\
\hline 19.57 & 0 & 2 & 1977 & 1 & 4 \\
\hline 1958 & 0 & 6 & 1978 & 1 & 5 \\
\hline 1959 & 0 & 1 & 1979 & 1 & 2 \\
\hline 1960 & 1 & 5 & 19.80 & 0 & 4 \\
\hline 1961 & 1 & 2 & 19.81 & 0 & 3 \\
\hline
\end{tabular}


Tabela 5 - Ordem cronológica da duração (em nümero de dias secos con secutivos) das estiagens mais longas e das precipitações máximas no período de um dia, observadas na cidade de Itapeva, SP, nos anos de 1942 a 1981.

\begin{tabular}{|c|c|c|c|c|c|}
\hline ANO & Estiagem & Precipitação & ANO & Estiagem & Precipitação \\
\hline 1942 & 45 & 66,1 & 1962 & 26 & 67,3 \\
\hline 1943 & 59 & 62,0 & 1963 & 75 & 80,1 \\
\hline 1944 & 62 & 69,6 & 1964 & 27 & 91,6 \\
\hline 1945 & 31 & 85,6 & 1965 & 21 & 131,1 \\
\hline 1946 & 17 & 82,7 & 1966 & 23 & 70,3 \\
\hline 1947 & 19 & 77,5 & 1967 & 49 & 58,7 \\
\hline 1948 & 34 & 65,6 & 1968 & 29 & 55,4 \\
\hline 1949 & 30 & 98,8 & 1969 & 24 & 58,6 \\
\hline 1950 & 57 & 52,6 & 1970 & 40 & 104,6 \\
\hline 1951 & 27 & 39,6 & 1971 & 21 & 68,2 \\
\hline 1952 & 39 & 83,5 & 1972 & 21 & 68,7 \\
\hline 1953 & 31 & 65,5 & 1973 & 18 & 105,2 \\
\hline 1954 & 58 & 75,5 & 1974 & 28 & 101,2 \\
\hline 1955 & 29 & 59,0 & 1975 & 25 & 68,8 \\
\hline 1956 & 20 & 59,1 & 1976 & 16 & 74,1 \\
\hline 1957 & 19 & 75,1 & 1977 & 23 & 93,5 \\
\hline 19.58 & 24 & 49,9 & 19.78 & 24 & 54,6 \\
\hline 1959 & 29 & 58,5 & 19.79 & 23 & 73,8 \\
\hline 1960 & 49 & 57,2 & 19.80 & 17 & 79,2 \\
\hline 1961 & 71 & 59,9 & 1981 & 21 & 59,7 \\
\hline
\end{tabular}


Tabela 6 - Ordem cronológica do número de ocorrências anuais de estiagens de duração não inferior a 30 dias secos consecutivos e de aguaceiros de altura não inferior a $50 \mathrm{~mm}$, ob servadas na cidade de Itapeva, SP, no período de 1942 a 1981 .

\begin{tabular}{|c|c|c|c|c|c|}
\hline ANO & Estiagem & Aguaceiro & ANO & Estiagem & Aguaceiro \\
\hline 1942 & 1 & 5 & 1962 & 0 & 1 \\
\hline 1943 & 4 & 3 & 1963 & 2 & 1 \\
\hline 1944 & 1 & 1 & 1964 & 0 & 2 \\
\hline 1945 & 1 & 4 & 1965 & 0 & 2 \\
\hline 1946 & 0 & 7 & 1966 & 0 & 2 \\
\hline 1947 & 0 & 4 & 1967 & 2 & 2 \\
\hline 1948 & 1 & 1 & 1968 & 0 & 1 \\
\hline 1949 & 0 & 2 & 1969 & 0 & 1 \\
\hline 1950 & 1 & 4 & 1970 & 1 & 5 \\
\hline 1951 & $a$ & 0 & 1971 & 0 & 1 \\
\hline 19.52 & 1 & 2 & 1972 & 0 & 5 \\
\hline 1953 & 1 & 1 & 1973 & 0 & 4 \\
\hline 1954 & 1 & 3 & 1974 & 0 & 2 \\
\hline 19.55 & 0 & 3 & 1975 & 0 & 1 \\
\hline 19.56 & 0 & 1 & 1976 & 0 & 4 \\
\hline 1957 & 0 & 6 & 1977 & 0 & 2 \\
\hline 1958 & 0 & 1 & 1978 & 0 & 2 \\
\hline 19.59 & 0 & 1 & 1979 & 0 & 4 \\
\hline 1960 & 2 & 4 & 1980 & 0 & 2 \\
\hline 1961 & 1 & 0 & 1981 & 0 & 2 \\
\hline
\end{tabular}


Tabela 7 - Dados originais, referentes a Presidente Prudente,

no ano de 1958, para precìpícação máxima e estiagem.

ACCO - PRESIDENTE PRUDENTE - - PREFIXO D8-3

\begin{tabular}{|c|c|c|c|c|c|c|c|c|c|c|c|c|}
\hline \multirow[b]{2}{*}{ DIAS } & \multicolumn{8}{|c|}{ ALTURAS MENSAIS DE CHUVA (mm) } & \multicolumn{4}{|c|}{ - ANO: - $195 \mathrm{~S}$} \\
\hline & JAN. & FEV. & MAR. & $A B A$. & $M A I O$ & JUN. & JUL. & A G 0. & SET. & ou $\tau$. & NOY. & DEZ. \\
\hline 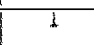 & 0,0 & 0,0 & 3,3 & 30,9 & 0,0 & 0,0 & 0,0 & 0,0 & 0,0 & 3,0 & 3,1 & 2,5 \\
\hline 2 & 0,0 & 0,0 & 0,0 & 0,0 & 11,7 & 0,0 & 0,0 & 0,0 & 0,0 & 0,0 & $\tilde{0}, 0$ & 13,6 \\
\hline 3 & 0,0 & 8,4 & 0,0 & 0,0 & 17,5 & 0,0 & 0,0 & 0,0 & 0,0 & 0,0 & 0,0 & 0,0 \\
\hline 4 & 0,0 & 2,8 & 0,0 & 0,0 & 0,0 . & 0,0 & 0,0 & 0,0 & 0,0 & 0,0 & $: 7,9$ & 0,0 \\
\hline 5 & 0,0 & 4,9 & 0,0 & 0,0 & 0,0 & 0,0 & 0,0 & 0,0 & 0,0 & 0,0 & 0,0 & 0,0 \\
\hline 6 & 0,0 & 5,4 & 0,0 & 0,0 & 0,0 & 0,0 & 0,0 & 0,0 & 1,1 & 0,0 & 0,0 & 0,0 \\
\hline 7 & 0,0 & 8,1 & 1,5 & 0,0 & 0,0 & 0,0 & 0,0 & 0,0 & 4,6 & 0,0 & 0,0 & 1,7 \\
\hline 8 & 0,0 & 1,1 & 7,9 & 0,0 & 0,0 & 0,0 & 0,0 & 0,0 & 4,5 & 0,0 & 0,0 & 0,0 \\
\hline 9 & 0,0 & 0,0 & 0,0 & 5,6 & 0,0 & 0,0 & 0,0 & 0,0 & 0,0 & 0,0 & 0,0 & 24,5 \\
\hline 10 & 0,0 & 0,0 & 0,0 & 0,0 & 0,0 & 0,0 & 0,4 & 0,0 & 3,6 & 0,0 & 0,0 & 0,0 \\
\hline 11 & 0,0 & 0,0 & 0,0 & 0,0 & 0,6 & 0,0 & 31,9 & 0,0 & 0,0 & 17,8 & 0,0 & 7.4 \\
\hline 12 & $\therefore, 3$ & 0,0 & 0,0 & 0,0 & 0,0 & 0,0 & 0,0 & 0,0 & 0,0 & 0,0 & 4,6 & 10,8 \\
\hline 13 & 1,6 & 0,0 & 0,0 & 11,9 & 0,0 & 0,0 & 0,0 & 0,0 & 2,5 & 0,0 & $c, 0$ & 2,0 \\
\hline 14 & 0,0 & 0,0 & 0,6 & 0,0 & 0,0 & 22,5 . & 0,0 & 0,0 & $\beta 5,9$ & 0,0 & 0,0 & 0,0 \\
\hline is & 13,9 & 0,0 & 1,0 & 0,0 & 0,0 & 66,2 & 7,6 & 0,0 & $p_{1,6}$ & 0,0 & 0,0 & $\Xi 5$ \\
\hline 16 & 48,5 & 0,0 & 12,5 & 0,0 & 0,0 & 10,5 & 2,9 & 0,0 & 0,0 & 0,0 & 0,0 & 0,0 \\
\hline 17 & 3,7 & 0,7 & 28,4 & 0,0 & 0,0 & 1,9 & 0,0 & 0,0 & 0,0 & 5,9 & 0,0 & $\therefore, 5$ \\
\hline 18 & 60,7 & 14,6 & 0,0 & 2,5 & 0,0 & 0,0 & 2,0 & 0,0 & 0,0 & $0,0$. & 0,1 & 2,2 \\
\hline 19 & 0,3 & 0,3 & 0,0 & 1,9 & 0,0 & 0,0 & 0,0 & 0,0 & $c, 0$ & 0,0 & 4,2 & 35,2 \\
\hline 20 & $0 . r^{r}$ & 0,0 & 0,0 & 0,0 & $0 ; 0$ & 0,0 & 0,0 & 0,0 & $c, c$ & 0,0 & 19,3 & 9,5 \\
\hline 21 & 14,8 & 0,0 & 0,0 & 0,0 & 9,5 & 0,0 & 0,0 & $c, 0$ & 0,0 & 8,0 & $i, j$ & 2,7 \\
\hline 22 & 39,2 & 0,0 & 0,0 & 0,0 & 13,8 & 0,0 & 0,0 & 0,0 & 0,0 & 0,0 & 0,0 & 29,3 \\
\hline 23 & 0,0 & 18,6 & 0,0 & 0,0 & 0,9 & 0,0 & 0,0 & 0,0 & 0,0 & 0,0 & 13,9 & $c, 0$ \\
\hline 24. & 0,0 & 0,5 & 0,8 & 0,0 & 1,9 & 0,0 & 0,0 & 0,0 & 4,9 & 0,0 & $n, 0$ & 0,0 \\
\hline 25 & 0,0 & 16,6 & 0,0 & 0,0 & 18,0 & 0,0 & $0,0$. & $0,0$. & 3,7 & 0,0 & $c, 0$ & 0,0 \\
\hline 26 & 0,0 & 12,4 & 0,0 & 0,0 & 3,8 & $0,0$. & 13,2 & $c, 0$ & 2,5 & 4,9 & $c, 0$ & 0,0 \\
\hline 27 & 0,0 & 0,1 & 0,0 & 0,0 & 0,0 & 0,0 & 0,0 & 0,0 & 0,0 & 21,5 & 0,0 & $c, 0$ \\
\hline 28 & $0,0$. & 0,0 & 0,0 & 0,0 & 7,8 & 0,0 & 0,0 & 0,0 & $0, \mathrm{C}$ & $\mathrm{Cl}_{1}, 2$ & 0,0 & 0,0 \\
\hline 29 & 0,0 & & 0,0 & 0,0 & 0,0 & 0,0 & 0,0 & 12,2 & 0,0 & 0,0 & 0,0 & 0,0 \\
\hline 30 & 10,9 & & 20,8 & 0,0 & 0,0 & 0,0 & 0,0 & 0,0 & 0,0 & 0,0 & 0,0 & 0,0 \\
\hline 31 & 0,0 & & 3,8 & & 0,0 & & 0,0 & 0,0 & & $0, c$ & & 0,0 \\
\hline & & & & & $A L O ̂ R E$ & $S M E$ & ISAIS & & & & & \\
\hline Tolais & 200,7 & 94,5 & 77,3 & 52,8 & 85,5 & 101,1 & 58,0 & 12,2 & 94,9 & 111,3 & 21,3 & $151, \therefore$ \\
\hline Percent. & 17,7 & 8,4 & 6,8 & 4,6 & 7,5 & 9,0 & 5,1 & 1,1 & 8,5 & 9,8 & 8,2 & 13,5 \\
\hline Máxima & 60,9 & 18,6 & 28,4 & 30,9 & 18,0 & 6ú,2 & 31,9 & 12,2 & 35,9 & 61,2 & 43,9 & 35,2 \\
\hline \begin{tabular}{|l|}
$\begin{array}{l}\text { Dias de } \\
\text { Chuva }\end{array}$ \\
\end{tabular} & 11 & 14 & 9 & 5 & 10 & 4 & 6 & 1 & 10 & 5 & $?$ & 14 \\
\hline & alötes & is. & & de & a: $\quad 96$ & & Máxima: & 66,2 & Iotal: & $=1131$, & & \\
\hline
\end{tabular}


18.

Tabela 8 - Dados originais, referentes a Presidente Prudente, Sp, no ano de 1958, para ocorrências de aguaceiros e estiagens.

\begin{tabular}{|c|c|c|c|c|c|c|c|c|c|c|c|c|}
\hline \multirow[b]{2}{*}{$D I A S$} & \multicolumn{4}{|c|}{ ALTURAS } & \multicolumn{4}{|c|}{ MEHSAIS DE CHUYA (mm) } & \multicolumn{4}{|c|}{ - ANO - 1958} \\
\hline & J A N: & FEV. & MAR. & A B R. & M.A10 & JUN. & JUL. & $A \subset 0$ & SET. & OU T. & xоY. & DEZ. \\
\hline 1 & 0,0 & $\overline{0}, \overline{0}$ & 0,0 & 30,9 & 0,0 & 0,0 & 0,0 & 0,0 & 0,0 & 0,0 & 0,1 & 2,5 \\
\hline 2 & 0,0 & 0,0 & 0,0 & 0,0 & 11,7 & 0,0 & 0,0 & 0,0 & 0,0 & 0,0 & 0,0 & 13,6 \\
\hline 3 & 0,0 & 8,4 & 0,0 & 0,0 & 17,5 & 0,0 & 0,0 & 0,0 & 0,0 & 0,0 & 0,0 & 0,0 \\
\hline 4 & 0,0 & 2,8 & 0,0 & 0,0 & 0,0 & 0,0 & 0,0 & 0,0 & 0,0 & 0,0 & 17,9 & 0,0 \\
\hline 5 & 0,0 & 4,9 & 0,0 & 0,0 & 0,0 & 0,0 & 0,0 & 0,0 & 0,0 & 0,0 & 0,0 & 0,0 \\
\hline 6 & 0,0 & 5,4 & 0,0 & 0,0 & 0,0 & 0,0 & $0,0$. & 0,0 & 2,1 & 0,0 & 0,0 & 0,0 \\
\hline 7 & 0,0 & 8,1 & 1,5 & 0,0 & 0,0 & 0,0 & 0,0 & 0,0 & 4,6 & 0,0 & 0,0 & 1,7 \\
\hline 8 & 0,0 & 1,1 & 7,9 & 0,0 & 0,0 & 0,0 & 0,0 & 0,0 & 4,5 & 0,0 & $0, \mathrm{c}$ & 0,0 \\
\hline 9 & 0,0 & 0,0 & 0,0 & 5,6 & 0,0 & 0,0 & 0,0 & 0,0 & 0,0 & 0,0 & 0,0 & 24,5 \\
\hline 10 & $.0,0$ & 0,0 & 0,0 & 0,0 & 0,0 & 0,0 & 0,4 & 0,0 & 0,6 & 0,0 & 0,0 & 0,0 \\
\hline 11 & 0,0 & 0,0 & 0,0 & 0,0 & 0,6 & 0,0 & 31,9 & 0,0 & 0,0 & 17,8 & $0,0$. & 2,4 \\
\hline 12 & $\dot{0}, 3$ & 0,0 & 0,0 & 0,0 & 0,0 & 0,0 & 0,0 & 0,0 & 0,0 & 0,0 & $\therefore 6$ & 10,0 \\
\hline 13 & 1,6 & 0,0 & 0,0 & 11,9 & 0,0 & 0,0 & $0,0$. & 0,0 & 2,5 & 0,0 & $c, 0$ & 2,0 \\
\hline 14 & 0,0 & 0,0 & 0,6 & 0,0 & 0,0 & 22,5 & 0,0 & 0,0 & 35,9 & 0,0 & 0,0 & 0,0 \\
\hline 15 & 13,9 & 0,0 & 1,0 & 0,0 & 0,0 & 66,2 & 7,6 & 0,0 & 21,6 & 0,0 & 0,0 & 3,5 \\
\hline 16 & 48,5 & 0,0 & 12,5 & 0,0 & 0,0 & 10,5 & 2,9 & 0,0 & 0,3 & 0,0 & $c, 0$ & 0,0 \\
\hline 17 & 3,7 & 0,7 & 28,4 & 0,0 & 0,0 & 1,9 & 0,0 & 0,0 & 0,0 & 5,9 & $c, 0$ & $\therefore, 5$ \\
\hline 18 & 60,91 & 14,6 & 0,0 & 2,5 & 0,0 & 0,0 & 2,0 & 0,0 & 0,0 & 0,0 & 0,3 & 2,2 \\
\hline 19 & 0,3 & 0,3 & 0,0 & 1,9 & 0,0 & 0,0 & 0,0 & 0,0 & $c, 0$ & 0,0 & $\therefore, 2$ & 35,2 \\
\hline 20 & $0 .{ }^{n}$ & 0,0 & 0,0 & 0,0 & 0,0 & 0,0 & 0,0 & 0,0 & $\therefore, c$ & 0,0 & 19,9 & 9,5 \\
\hline 21. & 14,8 & 0,0 & 0,0 & 0,0 & 9,5 & 0,0 & 0,0 & $c, 0$ & 0,0 & 8,0 & 1,3 & 2,7 \\
\hline 22 & 39,2 & 0,0 & 0,0 & 0,0 & 13,8 & 0,0 & 0,0 & 0,0 & 0,0 & 0,0 & 0,0 & 29,3 \\
\hline 23 & 0,0 & 18,6 & 0,0 & 0,0 & 0,2 & 0,0 & 0,0 & 0,0 & 0,0 & 0,0 & 1),9 & $c, 0$ \\
\hline 24 & 0,0 & 0,5 & 0,8 & 0,0 & 1,9 & 0,0 & 0,0 & 0,0 & 4,9 & $i, c$ & 0,0 & 0,0 \\
\hline 25 & 0,0 & 16,6 & 0,0 & 0,0 & 18,0 & 0,0 & 0,0 & 0,0 & 3,7 & $0, c$ & $c, c$ & 0,0 \\
\hline 26 & 0,0 & 12,4 & 0,0 & 0,0 & 3,8 & 0,0 & 13,2 & $c, 0$ & 2,5 & 4,9 & 0,0 & 0,0 \\
\hline 27 & 0,0 & 0,1 & 0,0 & 0,0 & 0,0 & 0,0 & 0,0 & 0,0 & 0,0 & 21,5 & 0,0 & $c, 0$ \\
\hline 28 & 0,0 & 0,0 & 0,0 & 0,0 & 7,8 & 0,0 & 0,0 & 0,0 & $0, c$ & $(1,2 \pi$ & 0,0 & 0,0 \\
\hline 29 & 0,0 & & 0,0 & 0,0 & 0,0 & 0,0 & 0,0 & 12,2 & 0,0 & $\frac{0,0}{0,}$ & 0,0 & 0,0 \\
\hline 30 & 10,9 & & 20,8 & 0,0 & 0,0 & 0,0 & 0,0 & 0,0 & 0,0 & 0,0 & 0,0 & 0,0 \\
\hline 31 & 0,0 & & 3,8 & & 0,0 & & 0.0 & 0,0 & & $0, c$ & & 0,3 \\
\hline & & & & & ALÔRES & S $M E K$ & ISAIS & & & & & \\
\hline Tolais & 200,7 & 94,5 & 77,3 & 52,8 & 85,5 & 101,1 & 58,0 & 12,2 & 94,9 & 111,3 & 21,3 & $151, \therefore$ \\
\hline Percedl. & 17,7 & 8,4 & 6,8 & 4,6 & 7,5 & 9,0 & 5,1 & 1,1 & 8,5 & 9,8 & 0,1 & 13,6 \\
\hline Mixima & 60,9 & 18,6 & 28,4 & 30,9 & 18,0 & $6 u ́, 2$ & 31,9 & 12,2 & 35,9 & 61,2 & 43,9 & $3 i, 2$ \\
\hline $\begin{array}{l}\text { Dias de } \\
\text { Cbova }\end{array}$ & 11 & 14 & 9 & 5 & 10 & 4 & 6 & 1 & 10 & 5 & 7 & 14. \\
\hline & Palores & ais: & de & ias de & : 96 & & Màxima: & 66,2 & Tolal & 1131, & & \\
\hline
\end{tabular}


Por exemplo, no ano de 1958, para a Tabela 7 tem-se: a estiagem mais longa desse ano tem 33 dias secos consecutivos (27/07, 28/08), e a precipitação máxima registrada no ano foi 66,2 mm (15/06).

$\begin{array}{cccc}\text { Na Tabela 1: } & \text { ANO } & \text { ESTIAGEM } & \text { PRECIPITAÇÃO } \\ & 1958 & 33 & 66,2\end{array}$

Para a Tabela 8, no ano de 1958, tem-se que ocorreu uma estiagem com duração não inferior a 30 dias secos consecutivos $(27 / 07,28 / 08)$ e ocorreram três aguaceiros de altura não inferior a $50 \mathrm{~mm}: 60,9(18 / 01), 66,2(15 / 06)$ e $61,2(28 / 10)$.

Na Tabela 2: ANO ESTIAGEM AGUACEIRO

$1958 \quad 3$

\section{2 - Metodologia}

De acordo com a teoria dos valores extremos de Gumbel, verificar-se-á inicialmente se alguma distribuição do tipo exponencial ajusta-se aos dados das Tabelas 1,3 e 5 .

A distribuição normal e a distribuição lognormal, in dicadas para o estudo de dados pluviométricos, são do tipo exponencial. Para dados de estiagem não há na bibliografia disponível indi cações de alguma distribuição tipo exponencial para o estudo desses dados. Optou-se, então, pelas duas distribuições do tipo exponencial indicadas por VIIELA e MATTCS (1980) para o estudo de dados pluviomét ricos. 
As funções de densidade de probabilidade da distribuição normal e da distribuição lognormal são dadas por:

a) NORMAL

$$
f_{x}(x ; \mu, \sigma)=\frac{1}{\sigma \sqrt{2 \pi}} e^{-\left[(x-\mu)^{2} / 2 \sigma^{2}\right]} ; \quad \begin{aligned}
&-\infty<x<\infty \\
&-\infty<\mu<\infty \\
& \sigma>0
\end{aligned}
$$

b) LOGNORMAL

$$
f_{x}(x ; \mu, \sigma)=\frac{1}{x \circ \sqrt{2 \pi}} e^{-\left[(\ln x-\mu)^{2} / 2 \sigma^{2}\right] ;} \quad \begin{aligned}
& 0<x<\infty \\
& 0<\mu<\infty \\
& \sigma>0
\end{aligned}
$$

Para verificar se os dados, tanto de estiagens como os de precipitação, se ajustam às funções de distribuiçãonormal e log momal, pode ser feita pelo teste de qui-quadrado, de acordo com FISZ (1963), observando as restrições apontadas por CAMPOS (1979). Tais restrições são:

a) Se o número de classes é $\mathrm{K}=2$, a frequência esperada mínima deve ser $\geqslant 5$

b) Se $K>2$, o teste de $x^{2}$ não deve ser usado se maís de $20 \%$ das fre quências esperadas forem abaixo de 5 (cinco) ou se qualquer uma delas for inferior a 1 (um).

o objetivo desta parte do presente trabalho é poder otter a função de distribuição do tipo exponencial mais indicada para esses tipos de dados obtidos (Tabelas 1, 3 e 5). 


\subsection{1 - A distribuição de Gumbel}

A função de distribuição dada por

$$
\mathrm{F}(\mathrm{x} ; \alpha, \mathrm{u})=\exp \left(-\mathrm{e}^{-\alpha(\mathrm{x}-\mathrm{u})}\right), \quad \begin{aligned}
-\infty<\mathrm{x} & <\infty \\
-\infty<\alpha & <\infty \\
u & >0
\end{aligned}
$$

è chamada de Distribuição de Gumbel, também conhecida por função de distribuição de valores extremos. A função de densidade correspondente é:

$$
\left.f(x)=\alpha \exp [-\alpha(x-u)] \cdot \exp f^{-\alpha(x-u)}\right],-\infty<x<\infty
$$

$\mathrm{Na}$ expressão 1 tem-se então que

$$
P=P[X \leq x]=F(x ; \alpha, u)=\exp \left\{-e^{-\alpha(x-u)}\right\}
$$

onde $\mathrm{P}$ è a probabilidade de um valor extremo ser menor ou igual a $\mathrm{x}$.

\subsubsection{1 - A obtenção dos parāmetros $\alpha$ e u}

A Distribuição de Gumbel contēm apenas dois parâmetros, sendo um parâmetro de posição (u) e um parâmetro de dispersão ( $\alpha$ ). De acordo com BANZATto (1973), esses parâmetros dependem da dis tribuição inicial e do tamanho da amostra.

Para a obtenção-das estimativas dos parâmetros, pode-se utilizar o Método dos Momentos : Para sua aplicação necessita-se apenas da definição de momento. 
Definição: Se X é uma variável aleatöria com função de densidade $f(x)$, o momento de ordem $r$ em relação à origem da variável aleatoo ria $X$ é definido como sendo o valor esperado de $x^{r}$, isto $\bar{e}, E\left[x^{r}\right]$. Tem-se, então, no caso da distribuição de Gumbel,

$$
\mu_{r}^{\prime}=E\left[x^{r}\right]=\int_{-\infty}^{\infty} x^{r} \alpha e^{-\alpha(x-u)} e^{-e^{-\alpha(x-u)}} d x .
$$

0 primeiro momento em relação à origem da v.a. X ē a média, isto é, $\mu_{x}=\mu_{I}^{\prime}$.

Para a distribuição de Gumbel, a média da distribuição define-se por:

$$
\mu_{x}=\int_{-\infty}^{\infty} x \alpha e^{-\alpha(x-u)} e^{-e^{-\alpha(x-u)}} d x
$$

$\mathrm{Na}$ resolução da integral (1) utiliza-se a transforma ção

$$
z=e^{-\alpha(x-u)}
$$

o intervalo $(-\infty, \infty)$ torna-se $(\infty, 0)$, e

$$
x=u-\frac{1}{\alpha} \ln z \quad ; \quad \mathrm{dx}=-\frac{1}{\alpha z} \mathrm{~d} z
$$

Tem-se, então,

$$
\begin{aligned}
& \mu_{x}=\int_{\infty}^{0}\left(u-\frac{1}{\alpha} \ln z\right) \alpha z e^{-z} \cdot \frac{-1}{\alpha z} d z \\
& \mu_{x}=-\int_{0}^{\infty}\left(u-\frac{1}{\alpha} \ln z\right) e^{-z} d z
\end{aligned}
$$




$$
\mu_{x}=\int_{0}^{\infty} u e^{-z} d z-\frac{1}{\alpha} \int_{0}^{\infty} \ln z e^{-z} d z ;
$$

mas,

$$
\int_{0}^{\infty} e^{-z} d z=1
$$

e

$$
\int_{0}^{\infty} \ln z e^{-z}=\Gamma^{\prime}(1)=-\gamma=-0,577216 \quad \begin{gathered}
\text { (constante de } \\
\text { Euzer) }
\end{gathered}
$$

tem-se, então:

$$
\begin{aligned}
& \mu_{x}=u+\frac{1}{\alpha} \gamma \\
& \mu_{x}=u+\frac{1}{\alpha} \cdot 0,577216,
\end{aligned}
$$

que é a média da variável aleatória X com distribuição de Gumbel.

A variāncia da v.a. X é dada por

$$
\sigma^{2}=\mu_{2}^{\prime}-\left[\mu_{1}^{\prime}\right]^{2}=E\left[X^{2}\right]-\{E[X]\}^{2} .
$$

Tem-se, então:

$$
\sigma^{2}=\int_{-\infty}^{\infty} x^{2} \alpha e^{-\alpha(x-u)} e^{-e^{-\alpha(x-u)}} d x-\left[\mu_{x}\right]^{2}
$$

Na resolução da integral (2) utiliza-se novamente a transformação

$$
z=e^{-\alpha(x-u)},
$$

obtendo-se, então: 


$$
\begin{aligned}
\sigma^{2} & =\int_{0}^{\infty}\left(u-\frac{1}{\alpha} \ln z\right)^{2} e^{-z} d z-\left[\mu_{x}\right]^{2} \\
& =\int_{0}^{\infty}\left(u^{2}-\frac{2 u}{\alpha} \ln z+\frac{1}{\alpha^{2}} l n^{2} z\right) e^{-z} d z-\left[\mu_{x}\right]^{2} \\
& =\int_{0}^{\infty} u^{2} e^{-z} d z-\frac{2 u}{\alpha} \int_{0}^{\infty} \ln z e^{-z} d z+\frac{1}{\alpha^{2}} \int_{0}^{\infty} \ell n^{2} z e^{-z} d z-\left[\mu_{x}\right]^{2}
\end{aligned}
$$

Mas,

$$
\int_{0}^{\infty} \ln ^{2} z e^{-z}=\Gamma^{\prime \prime}(1)=\gamma^{2}+\frac{\pi^{2}}{6},
$$

então (3) torna-se

$$
\sigma^{2}=u^{2}-\frac{2 u}{\alpha}(-\gamma)+\frac{1}{\alpha^{2}}\left(\gamma^{2}+\frac{\pi^{2}}{6}\right)-\left[\mu_{x}\right]^{2}
$$

Mas,

$$
\mu_{x}=u+\frac{1}{\alpha} \gamma \Longrightarrow\left[\mu_{x}\right]^{2}=u^{2}+\frac{2 u}{\alpha} \gamma+\frac{1}{\alpha^{2}} \gamma^{2}
$$

então (4) torna-se

$$
\begin{aligned}
& \sigma^{2}=u^{2}+\frac{2 u}{\alpha} \gamma+\frac{1}{\alpha^{2}}\left(\gamma^{2}+\frac{\pi^{2}}{6}\right)-u^{2}-\frac{2 u \gamma}{\alpha}-\frac{1}{\alpha^{2}} \gamma^{2} \\
& \sigma^{2}=\frac{1}{\alpha^{2}} \frac{\pi^{2}}{6},
\end{aligned}
$$

que é a variância da v.a. X, que tem distribuição de Gumbel.

Para os parâmetros obtém-se, então

$$
u=\mu_{x}-\frac{1}{\alpha} \gamma \quad \text { e } \quad \alpha=\frac{4(4) \cdot \sigma}{1,282431 \cdot \sigma}
$$


3.2.1.2 - A estimativa dos parāmetros a e u

De acordo com GuMBEL (1941), para uma série de $\mathrm{N}$ observações de valores extremos, os parâmetros podem ser estimados a partir das estimativas da média aritmética (玄) e do desvio padrão (s) da sërie. Tem-se, então:

$$
\begin{aligned}
& \hat{\mathrm{u}}=\widehat{\mathrm{m}}-0,577216 \cdot \frac{1}{\hat{\alpha}} \\
& \frac{1}{\hat{\alpha}}=0,779769 \mathrm{~s} .
\end{aligned}
$$

\subsection{2 - A Distribuição de Poisson}

Uma variävel aleatória discreta $\mathrm{X}$ tem distribuiçãode Poisson se sua função de densidade é dada por:

$$
f(x)=\frac{e^{-\lambda} \lambda^{x}}{x !} \quad, \quad \lambda>0 ; x=0,1,2, \ldots
$$

A função geradora de momentos da variável aleatória $\mathrm{X}$ com função de distribuição de Poisson é dada por:

$$
\begin{aligned}
m_{X}(t)=E\left[e^{t X}\right] & =\sum_{x} e^{t x} \frac{e^{-\lambda} \lambda^{x}}{x !} \\
& =e^{-\lambda} \sum_{x} \frac{e^{t x} \lambda^{x}}{x !} \\
m_{X}(t) & =e^{-\lambda} \sum_{x} \frac{\left(\lambda e^{t}\right)^{x}}{x !}=e^{-\lambda} e^{\lambda e^{t}}
\end{aligned}
$$


A Esperança, E $[X]$, e a Variância, $V(x)$, da variável aleatória X são dadas por:

$$
\begin{aligned}
& m_{X}^{\prime}(t)=\lambda e^{-\lambda} e^{t} e^{\lambda e^{t}} \\
& \mu_{1}^{\prime}=m_{X}^{\prime}(0)=\lambda e^{-\lambda} e^{\lambda}=\lambda=E[X] \\
& m_{X}^{\prime \prime}(t)=\lambda e^{-\lambda} e^{t} e^{\lambda e^{t}}\left[\lambda e^{t}+1\right] \\
& \mu_{2}^{\prime}=m_{x}^{\prime \prime}(0)=\lambda e^{-\lambda} e^{\lambda}[\lambda+1] \\
& =\lambda^{2}+\lambda=E\left[X^{2}\right] \\
& V[X]=E\left[X^{2}\right]-E[X] \\
& =\lambda^{2}+\lambda-(\lambda)^{2} \\
& \mathrm{~V}[\mathrm{X}]=\lambda \quad ; \quad \mathrm{E}[\mathrm{X}]=\lambda
\end{aligned}
$$

3.3 - Método de Cāiculo

A estimativa das durações mäximas provāveis da estia gem mais longa do ano e das precipitações mäximas prováveis em um dia foram calculadas utilizando-se a função dada pela equação:

$$
F(x)=e^{-e^{-\hat{\alpha}(x-\hat{u})}},
$$


para valores de $F(x)$ iguais a 0,$1 ; 0,2 ; 0,3 ; 0,4 ; 0,5 ; 0,6 ; 0,7 ; 0,8$; 0,$9 ; 0,95 ; 0,96 ; 0,98$ e 0,99 .

A verificação da compatibilidade dos dados com a dis tribuição de Gumbel pode ser feita pelo teste de $x^{2}$, observando-se as restrições mencionadas por CAMPOS (1979).

O cálculo da probabilidade de ocorrência de estiagens com duração não inferior a 30 dias secos consecutivos, e de aguaceiros de altura não inferior a $50 \mathrm{~mm}$, foi feito mediante a aplicação da função de distribuição de Poisson. Para o cálculo da probabilidade de ocorrerem exatamente $\mathrm{K}$ estiagens ou $\mathrm{K}$ aguaceiros durante o ano utili za-se, então, a equação:

$$
P[X=k]=e^{-\hat{\lambda} t} \frac{(\hat{\lambda} t)^{K}}{K !} \quad, \quad K=0,1,2, \ldots
$$

onde $\hat{\lambda}$ é a média aritmética das ocorrências de estiagens e de aguaceiros no período de tempo(t) considerado (SCOTON E CRUZ, 1976).

A verificação da compatibilidade dos dados com a dis tribuição de Poisson pode ser feita pelo teste de $x^{2}$. 
28.

\section{RESULTADOS E DISCUSSÃO}

Para verificar, através do teste de qui-quadrado ao nível de 5\% de probabilidade, se é razoável admitir que os dados de estiagens da cidade de Presidente Prudente (Tabela 1) podem ser en quadrados numa distribui ção normal, com média estimada $\hat{\mu}=43,95$ e desvio padrão estimado $s=18,144647$, organizou-se uma distribuição de frequência com 6 classes,e a seguir estruturou-se o teste de $\chi^{2}$ (Ta bela 9).

Com 2 graus de Iiberdade, obteve-se:

$$
P\left|x^{2}>3,741556\right|=0,1540 \text {. }
$$

De acordo com o teste de $\chi^{2}$, os dados da estiagens da cidade de Presidente Prudente (Tabela 1) se ajustam à distribuição normal com parâtretros estimados $\hat{m}=43,95$ e $s=18,144647$. 


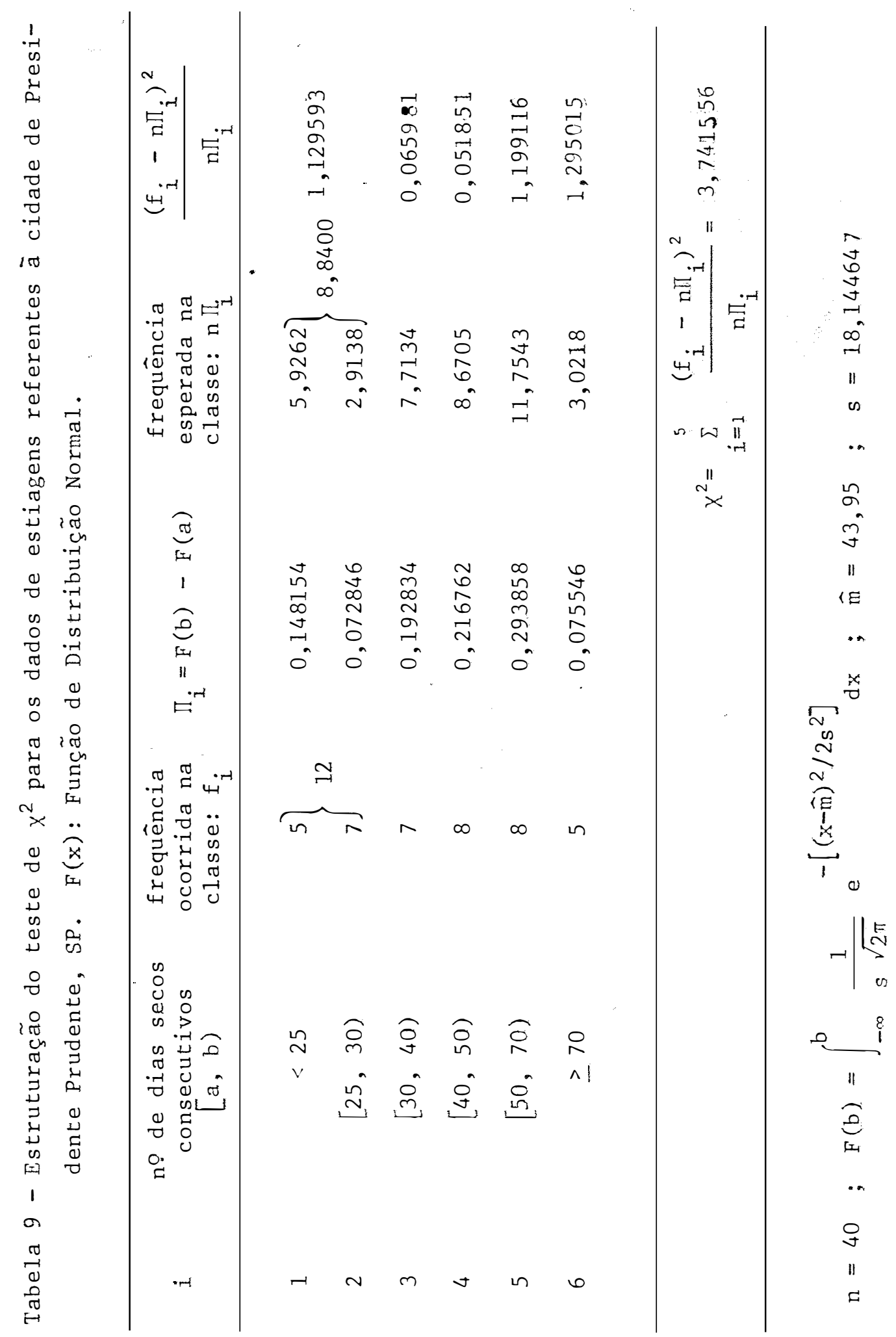


Verificou-se, a seguir, que esses dados podem ser en quadrados numa distribuição lognormal, com parâmetros estimados $\widehat{\mathrm{m}}=$ $=3,699343$ e $s=0,417078$.

Com 2 graus de liberdade, obteve-se:

$$
P\left[x^{2} \geq 2,053497:=0,3582 .\right.
$$

De acordo com o teste de $x^{2}$ (Tabela 10), os dados de estiagens referentes à cidade de Presidente Prudente se ajustam à dis tribuição lognormal, com parâmetros estimados $\hat{\mathrm{m}}=3,699343 \mathrm{e} \mathrm{s}=$ $=0,417078$.

$$
\text { Aplicando-se a esses dados a teoria proposta por Gum }
$$
bel, estimou-se a duração máxima provável da estiagem mais longa do ano (civil) e a probabilidade dessa estimativa não ser ultrapassada (Tabela 11).

Da Tabela 11 tem-se, por exemplo, que a duração máxi ma provāvel da estiagem mais longa do ano, com probabilidade de 95\% dessa estimativa não ser ultrapassada, è de 78 dias secos consecutivos.

A compatibilidade dos dados com a distribuição de Gum bel pode ser feita pelo teste de $\chi^{2}$ (Tabela 12).

Com 2 graus de liberdade obteve-se:

$$
P\left[x^{2} \geq 2,963189\right]=0,2273
$$


31.

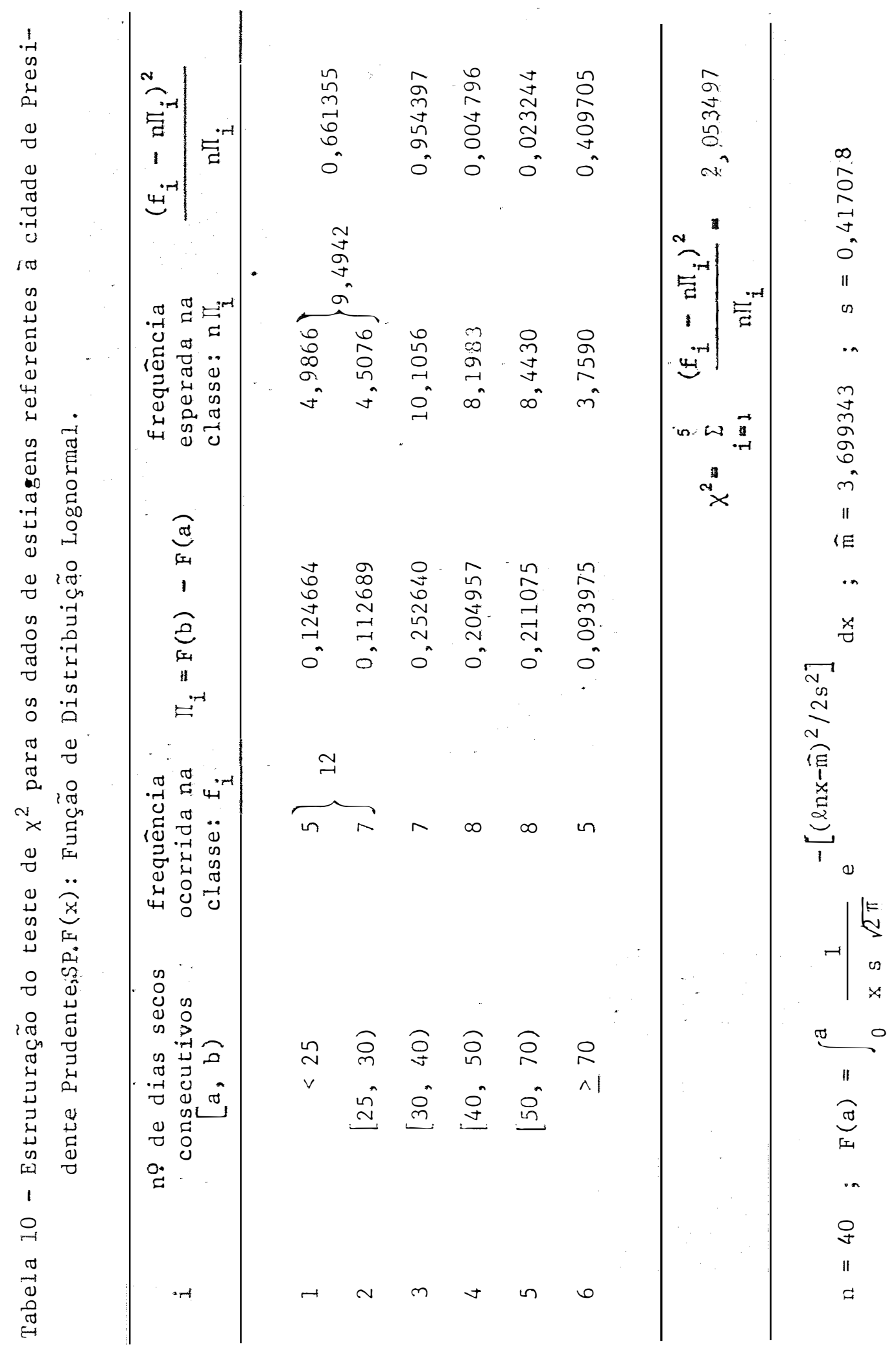


32.

Tabela 11 - Estimativas da duração máxima provāvel da estiagem mais longa do ano, em nümero de dias secos consecutivos e a probabilidade dessas estimativas não serem ultrapassadas, para a cidade de Presidente Prudente, SP.

Estimativas da duração máxima provāvel
Probabilidade das estimativas

não serem ultrapassadas
101

91

81

78

68

57

50

45

41

37

33

29

2.4
0,99

0,98

0,96

0,95

0,90

0,80

0,70

0,60

0,50

0,40

0,30

0,20

0,10 


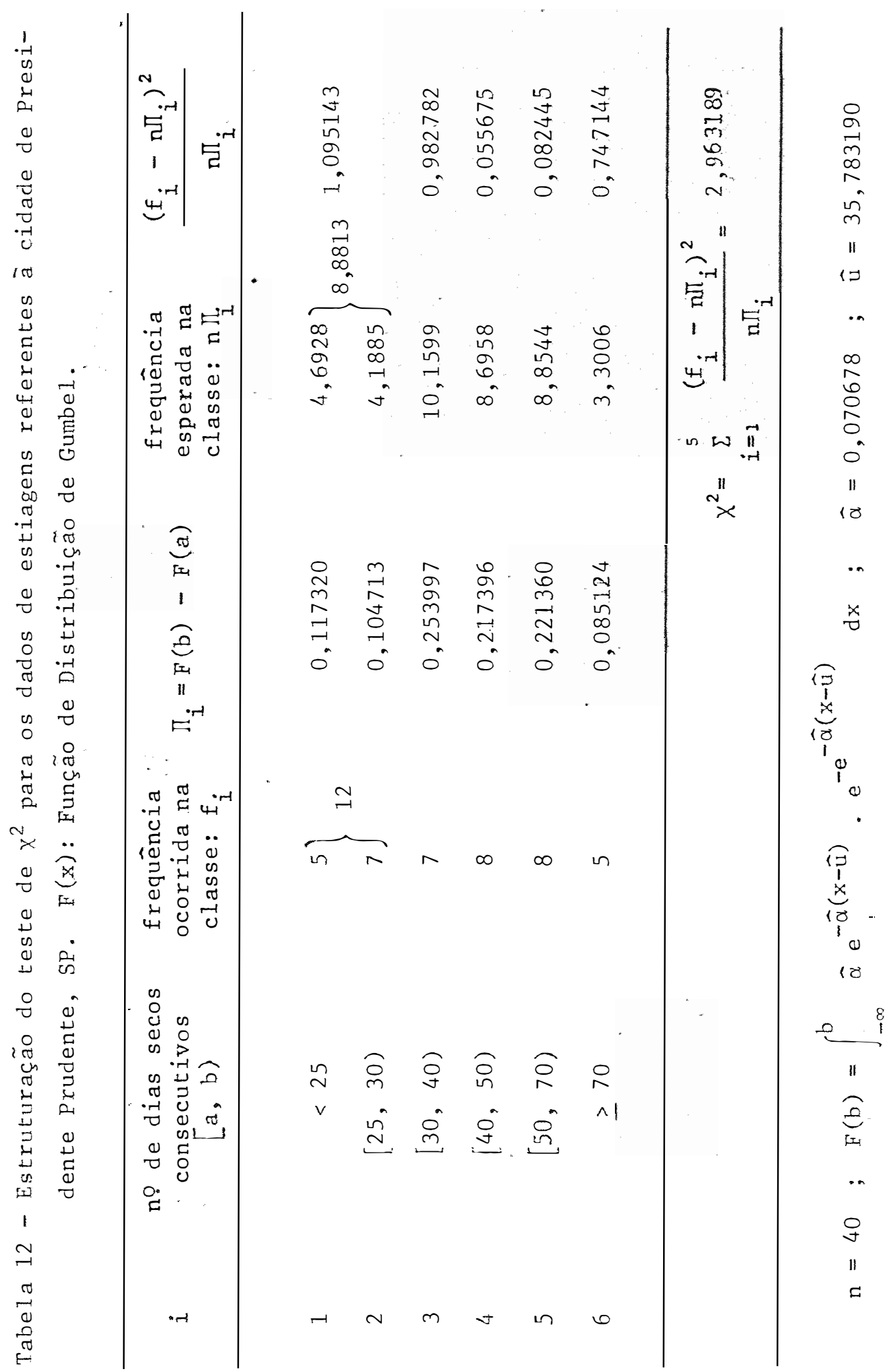


De acordo com o teste de $\chi^{2}$, os dados em estudo se ajustam à distribuição de Gumbel com parâmetros estimados $\hat{\alpha}=0,070678$ e $\hat{u}=35,783190$.

Nos 40 anos em estudo ocorreram 42 estiagens de dura ção não inferior a 30 dias secos consecutivos (Tabela 2). Logo, a mé dia anual è de 1,05.

Para o cálculo das probabilidades utilizou-se a distribuição de Poisson

$$
P[X=K]=e^{-1,05} \frac{(1,05)^{K}}{K !} \quad ; \quad K=0,1,2,3,4, \ldots
$$

Os resultados se encontram na Tabela 13.

Tabela 13 - Ocorrência de estiagensde duração não inferior a 30 dias secos consecutivos, durante 40 anos $(1942$, 1981) na cida de de Presidente Prudente, SP.

\begin{tabular}{|c|c|c|c|c|}
\hline \multirow{2}{*}{$\begin{array}{l}\text { VALORES DA } \\
\text { VARIĀVEL X }\end{array}$} & \multicolumn{3}{|c|}{ FREQUENCIA } & \multirow{2}{*}{$\begin{array}{l}\text { PROBABILIDADE } \\
\mathrm{P}_{i}\end{array}$} \\
\hline & Observada & $\left(f_{i}\right)$ & Esperada $\left(\mathrm{nP}_{i}\right)$ & \\
\hline 0 & 12 & \multirow{5}{*}{2} & 13,9960 & 0,3499 \\
\hline 1 & 16 & & 14,6960 & 0,3674 \\
\hline 2 & 10 & & 7,7160 & 0,1929 \\
\hline 3 & 2 & & $2,7000) 35920$ & 0,0675 \\
\hline$\geq 4$ & 0 & & $0,8920\}^{J, 28}$ & 0,0223 \\
\hline
\end{tabular}


Os valores da Tabela 13 permitem concluir que a probabilidade de que ocorra uma ou mals estiagem de duração não inferior a 30 dias secos consecutivos durante o ano é estimada em 0,6501 ou $65,01 \%$.

$$
P[X \geq 1]=0,6501
$$

Da Tabela 13 tira-se, ainda,

$$
P[X \leq 2]=0,9102
$$

A verificação da compatibilidade dos dados com a dis tribuição de Poisson pode ser feita pelo teste de $x^{2}$.

$$
\begin{gathered}
x^{2}=\sum_{i} \frac{\left(f_{i}-n P_{i}\right)^{2}}{{ }^{n P}}=0,2847+0,1157+0,6761+0,7056 \\
x^{2}=1,7820 .
\end{gathered}
$$

Com 2 graus de liberdade tem-se:

$$
P\left[x^{2} \geq 1,7820\right]=0,4102 \text {. }
$$

Verifica-se, pois, a validez da hipótese feita (isto $\bar{e}$, os dados se ajustam à distribuição de Poisson).

Com os dados de precipitação da Tabela 1, procedeu-se de maneira análoga à anterior. 
De acordo com a Tabela 14, para a distribuição normal com parâmetros estimados $\hat{\mathrm{m}}=87,915$ e $\mathrm{s}=38,136836$, obteve-se, para o teste de $\chi^{2}$ com 3 graus de liberdade

$$
P\left[x^{2} \geq 13,457847\right]=0,0037,
$$

e de acordo com a Tabela 15, para a distribuição lognormal com parâmetros estimados $\hat{\mathrm{m}}=4,407467$ e $\mathrm{s}=0,357548$, obteve-se

$$
\mathrm{P}\left[\mathrm{x}^{2} \geq 5,853470\right]=0,1190
$$

Tem-se, então, de acordo com o teste de $x^{2}$, que os dados em estudo podem ser enquadrados numa distribuição do tipo lognormal, com parâmetros estimados $\widehat{m}=4,407468$ e $s=0,357548$.

Aplicando-se aos dados de precipitação da Tabela 1 a distribuição de Gumbel com parâmetros estimados $\widehat{\alpha}=0,033627$ e. $\hat{u}=$ $=70,749796$, estimou-se, para o ano (civil) a precipitação mäxima pro vāvel para o período de um dia, e a probabilidade dessa estimativa não ser ultrapassada. Os resultados obtidos encontram-se na Tabela 16.

A compatibilidade dos dados com a distribuição de Gum bel pode ser feita pelo teste de $x^{2}$.

De acordo com a Tabela 17 , com 3 graus de liberdade, obteve-se

$$
P\left[x^{2} \geq 8,6979 \cdot 37\right]=0,0336 .
$$


37.

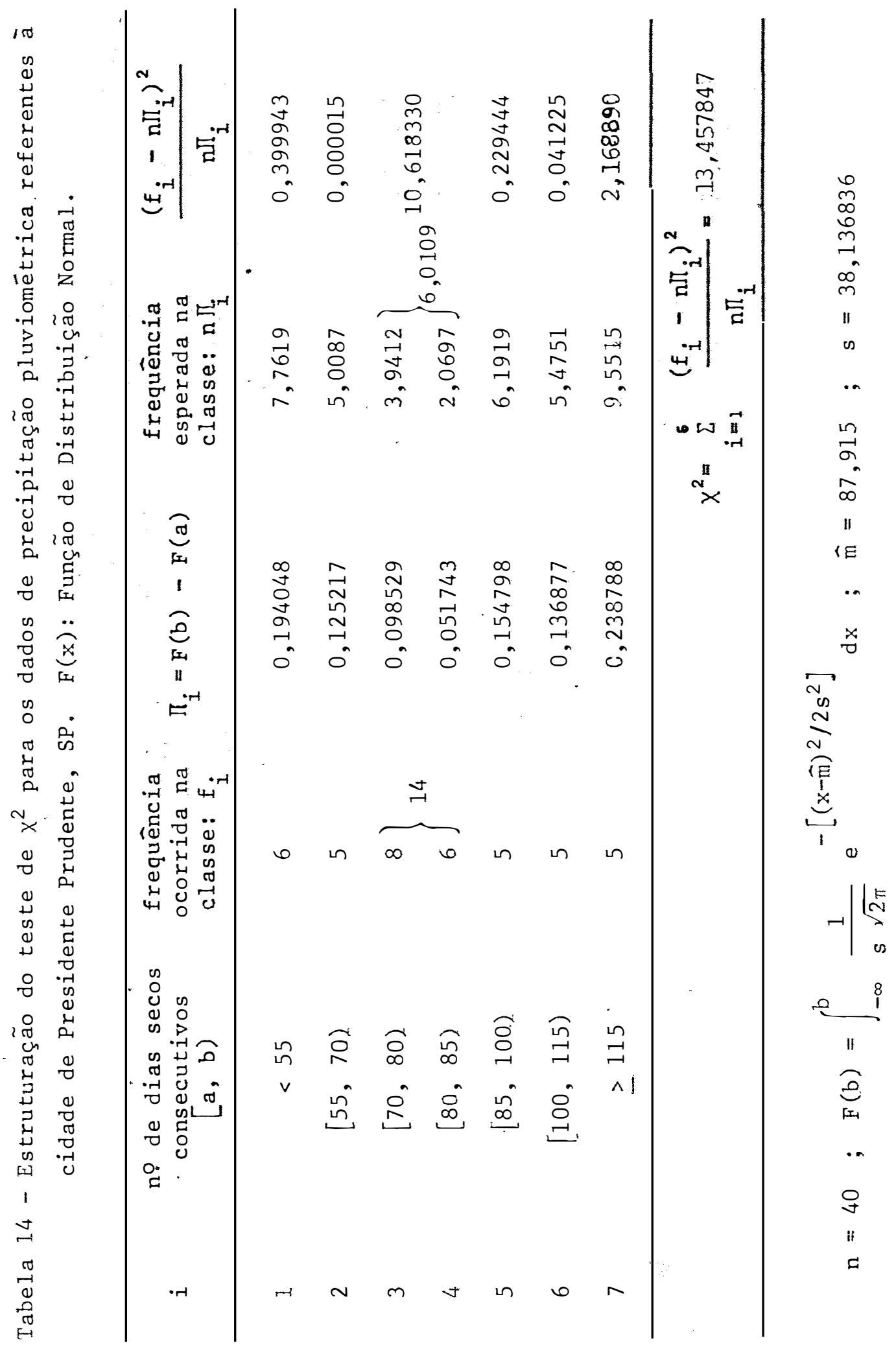


38.

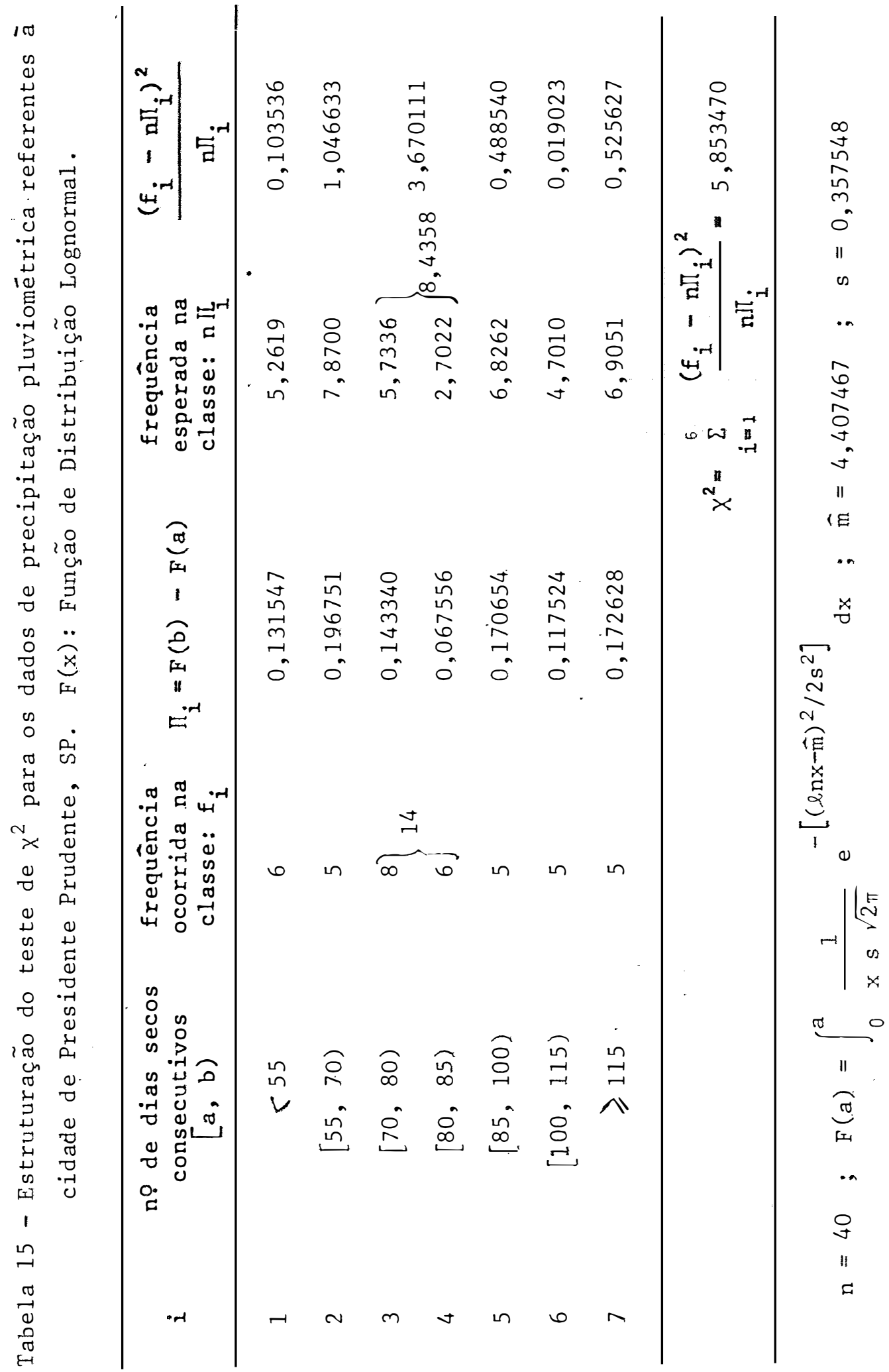


39.

Tabela 16 - Estimativas da precipitação māxima provável no períodode um dia, e a probabilidade dessas estimativas não serem ultrapassadas, para a cidade de Presidente Prudente, SP.

Estimativas da precipitação Probabilidade das estimativas máxima provável (m) não serem ultrapassadas

$\begin{array}{ll}207,5 & 0,99 \\ 186,8 & 0,98 \\ 165,9 & 0,96 \\ 159,1 & 0,95 \\ 137,7 & 0,90 \\ 115,4 & 0,80 \\ 101,4 & 0,50 \\ 90,7 & 0,60 \\ 81,7 & 0,50 \\ 73,3 & 0,40 \\ 65,2 & 0,30 \\ 56,6 & 0,20 \\ 45,9 & 0,10\end{array}$


40.

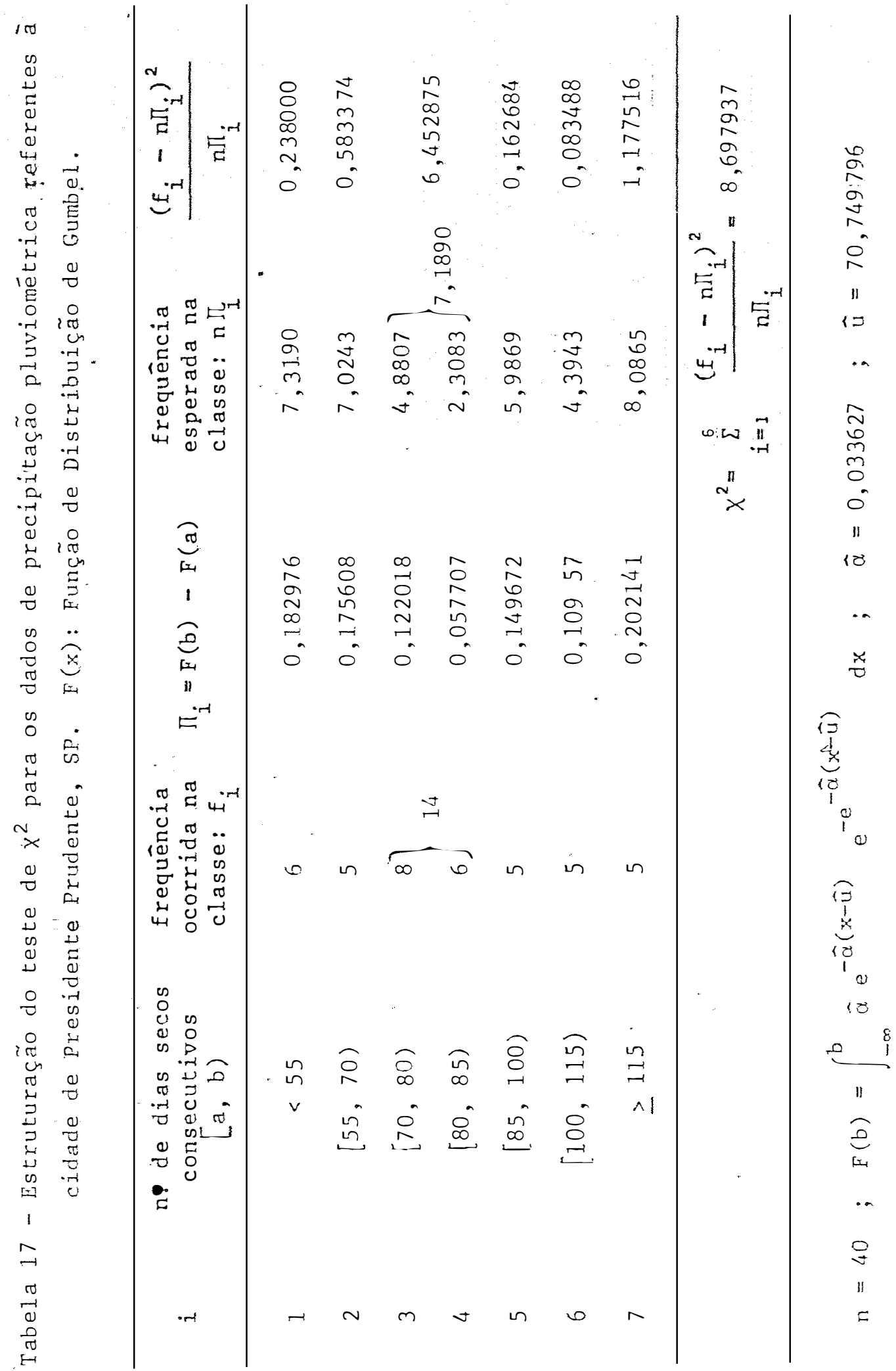


Segundo o teste de $x^{2}$, os dados em estudo não se ajus tam à distribuição de Gumbel com parâmetros estimados $\hat{\alpha}=0,033627 \mathrm{e}$ $\hat{u}=70,749796$; não se justificando portanto a estimativa da precipi tação maxima provāvel por esta distribuição.

Nos 40 anos em estudo, ocorreram 124 aguaceiros de altura não inferior a $50 \mathrm{~mm}$ (Tabela 2). Logo, a média anual é aproxi madamente 2,9524.

Para o cálculo das probabilidades utilizou-se a distribuição de Poisson

$$
P[X=K]=e^{-2,9524} \frac{(2,9524)^{K}}{K !} ; K=0,1,2,3,4, \ldots
$$

Os resultados obtidos encontram-se na Tabela 18.

Tabela 18 - Ocorrência de aguaceiros de altura não inferior a $50 \mathrm{~mm}$ durante 40 anos (1942, 1981), na cidade de Presidente Pru dente, SP.

\begin{tabular}{|c|c|c|c|c|c|c|}
\hline \multirow{2}{*}{\multicolumn{2}{|c|}{$\begin{array}{l}\text { VALORES DA } \\
\text { VARIÁVEL X }\end{array}$}} & \multicolumn{4}{|c|}{ F'REQUENCIA } & \multirow{2}{*}{$\begin{array}{c}\text { PROBABILIDADE } \\
\mathrm{P}_{\mathbf{I}}\end{array}$} \\
\hline & & Observada & $a\left(f_{i}\right)$ & Esperada & $\left(\mathrm{nP}_{i}\right)$ & \\
\hline & 0 & 27 & \multirow{3}{*}{11} & 1,4040 & \multirow{2}{*}{6,1080} & 0,0351 \\
\hline & 1 & 9 & & 4,7040 & & 0,1176 \\
\hline & 2 & 3 & & \multicolumn{2}{|l|}{7,8760} & 0,1969 \\
\hline & 3 & \multicolumn{2}{|l|}{11} & \multicolumn{2}{|l|}{8,7920} & 0,2198 \\
\hline & 4 & \multicolumn{2}{|l|}{4} & \multicolumn{2}{|l|}{7,3640} & 0,1841 \\
\hline & 5 & \multicolumn{2}{|l|}{7} & \multicolumn{2}{|l|}{4,9360} & 0,1234 \\
\hline & 6 & \multicolumn{2}{|l|}{$3)$} & \multicolumn{2}{|l|}{$2,7560)$} & 0,0689 \\
\hline & 7 & \multicolumn{2}{|c|}{$1\} 04$} & 1,3200 & 4,9320 & 0,0330 \\
\hline$\geqslant$ & 8 & 0 . & & $>0,8560$ & & 0,0214 \\
\hline
\end{tabular}


Da Tabela 18 tem-se que a probabilidade de que pelo menos um aguaceiro de altura excepcional ocorra durante o ano é esti mada em $96,49 \%$.

$$
P[X \geq 1]=0,9649
$$

A verificação da compatibilidade dos dados com a distribuição de Poisson pode ser feita pelo teste de $x^{2}$.

$$
\begin{aligned}
& x^{2}=\sum_{i} \frac{\left(f_{i}-n_{i}\right)^{2}}{n_{i} P_{i}}= 3,9181+3,0187+0,5545+ \\
&+1,5367+0,8631+0,1761 \\
& x^{2}=10,0672
\end{aligned}
$$

Com 5 graus de liberdade, tem-se

$$
P\left[x^{2} \geq 10,0672\right]=0,0734, \text { e o ajustamento }
$$

dos dados com a distribuição de Poisson é aceitável.

Para a cidade de Avaré, verificou-se, através do tes tes de qui-quadrado $\left(x^{2}\right)$, ao nível de $5 \%$ de probabilidade, se è razoāvel admitir que os dados de estiagens da Tabela 3 podem ser enqua drados numa das distribuições do tipo exponencial selecionadas nesse estudo.

De acordo com a Tabela 19, para a distribuição normal com parâmetros estimados $\hat{\mathrm{m}}=38,5$ e $\mathrm{s}=19,059959$, obteve-se:

$$
P\left[x^{2} \geq 10,001878\right]=0,006.7 \quad(2 \mathrm{~g} .1 .),
$$




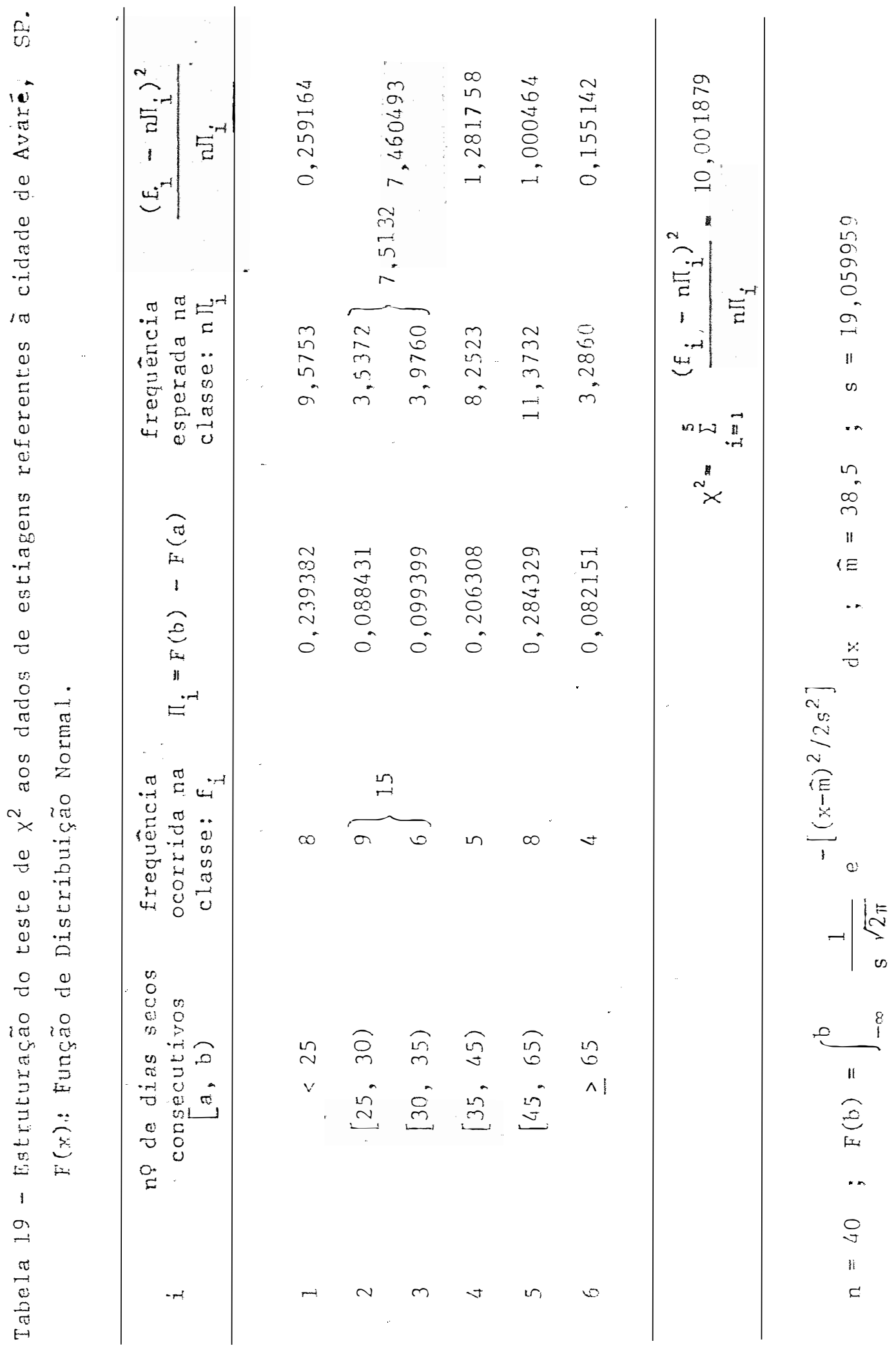


e de acordo com a Tabela 20, para a distribuição lognormal com parâmetros estimados $\hat{\mathrm{m}}=3,545936$ e $\mathrm{s}=0,453378$, obteve-se:

$$
P\left[x^{2} \geq 3,888932\right]=0,273700 \quad(3 \mathrm{~g} \cdot 1 .) \text {. }
$$

Os dados de estiagens, divididos em 6 classes de fre quência, ajustam-se à distribuição lognormal com parâmetros estima$\operatorname{dos} \hat{\mathrm{m}}=3,545936$ e $\mathrm{s}=0,453378$.

Aplicando-se a função de distribuição de Gumbel com parâmetros estimados $\hat{\alpha}=0,067284 \mathrm{e} \widehat{\mathrm{u}}=29,921205$ aos dados de estia gem da Tabela 3, estimou-se a duração máxima provável (em número de dias secos consecutivos) da estiagem mais longa do ano (civil) e a probabilidade dessa estimativa não ser ultrapassada. Os resultados ob tidos encontram-se na Tabela 21 .

A compatibilidade dos dados com a distribuição de Gum bel pode ser feita pelo teste de $x^{2}$.

De acordo com a Tabela 22, obteve-se:

$$
P\left[x^{2} \geq 4,567145\right]=0,1019 \quad(2 \mathrm{~g} \cdot 1 .)
$$

Tem-se, então, que os dados de estiagens da Tabela 3 ajustam-se à distribuição de Gumbel, com parâmetros estimados $\hat{\alpha}=$ $=0,067284$ e $\hat{u}=29,921205$. 
45.

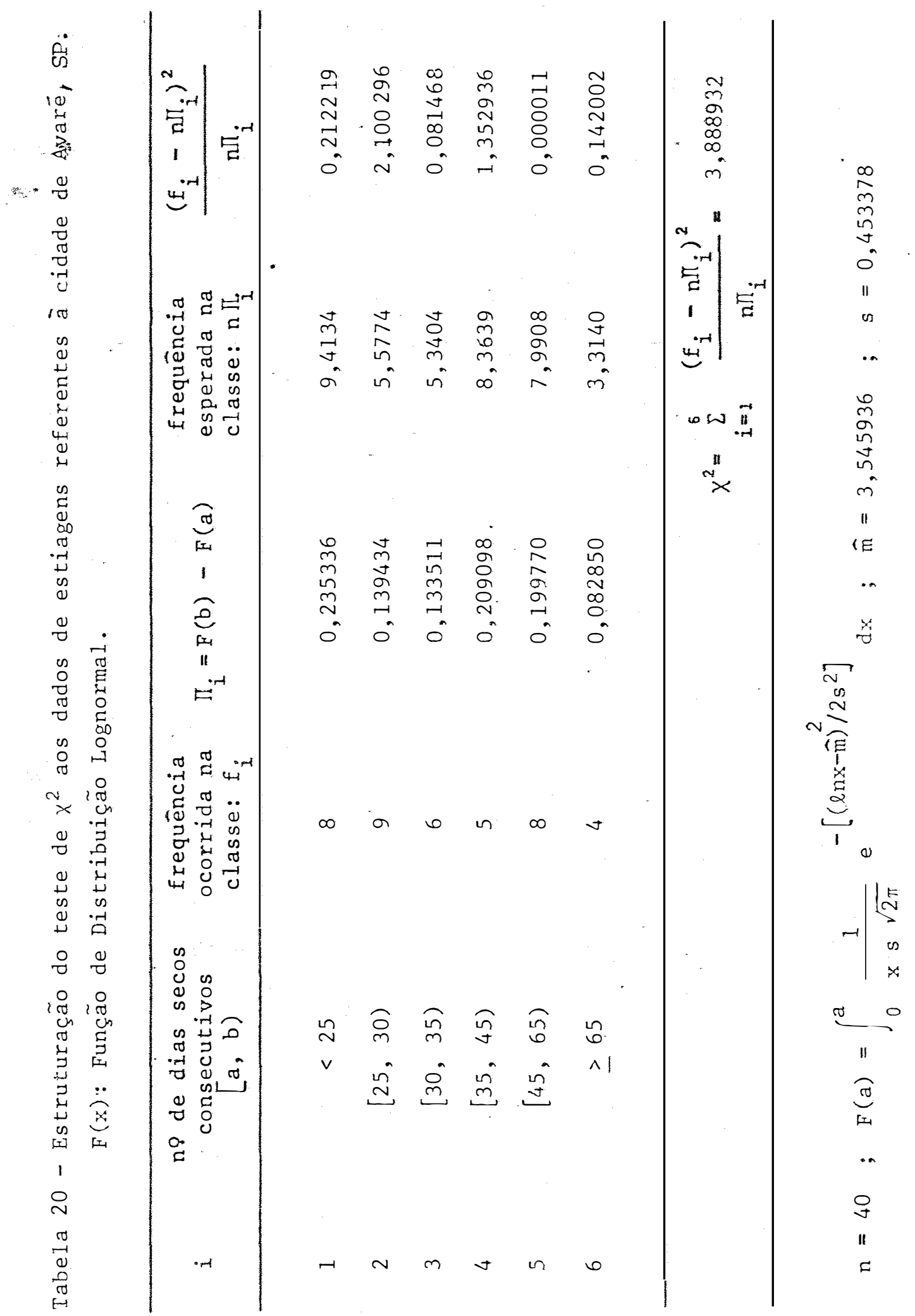


46.

Tabela 21 - Estimativas da duração mäxima provāvel da estiagem mass longa do ano, em nümero de dias secos consecutivos, e a probabilidade dessas estimativas não serem ultrapassadas, para a cidade de Avaré, SP.

\begin{tabular}{|c|c|}
\hline $\begin{array}{c}\text { Estimativas da duração } \\
\text { mäxima provável }\end{array}$ & $\begin{array}{c}\text { Probabilidade das estimativas } \\
\text { não serem ultrapassadas }\end{array}$ \\
\hline 98 & 0,99 \\
\hline 88 & 0,98 \\
\hline 77 & 0,96 \\
\hline 74 & 0,95 \\
\hline 63 & 0,90 \\
\hline 52 & 0,80 \\
\hline 45 & 0,70 \\
\hline 40 & 0,60 \\
\hline 35 & 0,50 \\
\hline 31 & 0,40 \\
\hline 27 & 0,30 \\
\hline 23 & 0,20 \\
\hline 18 & 0,10 \\
\hline
\end{tabular}




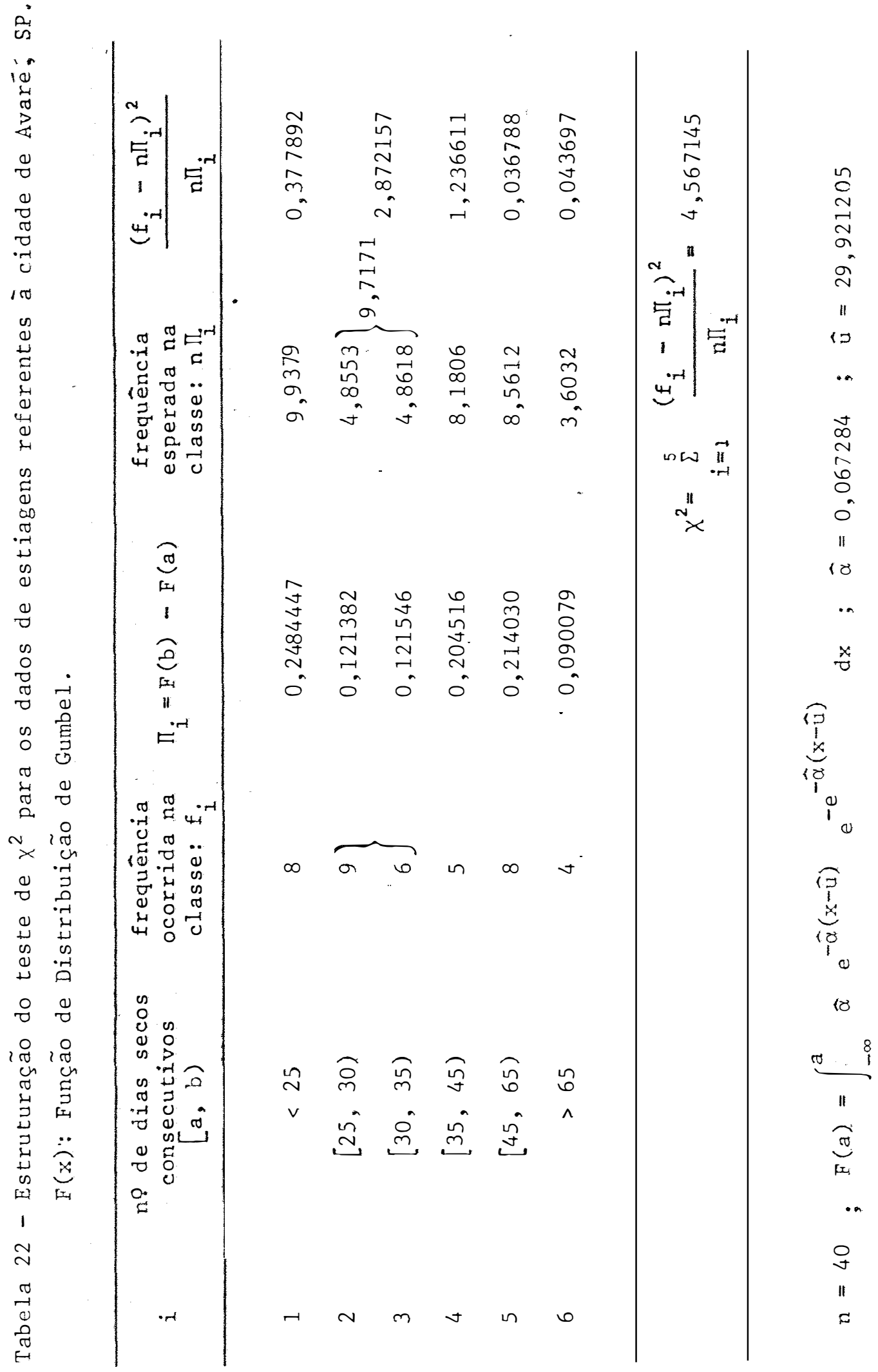


Nos 40 anos em estudo, ocorreram 29 estiagens de duração não inferior a 30 dias secos consecutivos (Tabela 4). Logo, a mëdia anual é aproximadamente 0,7222.

Para o cálculo das probabilidades utilizou-se a distribuição de Poisson

$$
P[X=K]=e^{-0,7222} \frac{(0,7222)^{K}}{K !} \quad ; \quad K=0,1,2,3, \ldots
$$

Os resultados obtidos encontram-se na Tabela 23.

Tabela 23 - Ocorrência de estiagensde duração não inferior a 30 dias secos consecutivos, durante 40 anos (1942, 1981), na cidade de Avaré, SP.

\begin{tabular}{|c|c|c|c|c|}
\hline \multirow{2}{*}{$\begin{array}{l}\text { VALORES DA } \\
\text { VARIĀVEL X }\end{array}$} & \multicolumn{3}{|c|}{ FREQUÊNCIA } & \multirow{2}{*}{$\begin{array}{c}\text { PROBABILIDADE } \\
\mathrm{P}_{i}\end{array}$} \\
\hline & Observada & $\left(f_{i}\right)$ & Esperada $\left(\mathrm{nP}_{i}\right)$ & \\
\hline 0 & 17 & \multirow{5}{*}{1} & 19,3720 & 0,4843 \\
\hline 1 & 18 & & 14,0440 & 0,3511 \\
\hline 2 & 4 & & 5,0920 & 0,1273 \\
\hline 3 & 1 & & 1,2280 & 0,0307 \\
\hline$\geqslant 4$ & 0 & & $0,2640\} 1,4920$ & 0,0066 \\
\hline
\end{tabular}

Da Tabela 23 tem-se que a probabilidade de ocorrêna de pelo menos uma estiagem de duração não inferior a 30 dias se is consecutivos é estimada en $51,57 \%$,

$$
P[X \geq 1]=0,5157
$$


Pode-se observar, tambëm, que

$$
P[X \leq 1]=0,8354 \text {. }
$$

A verificação da compatibilidade dos dados com a dis tribuição de Poisson pode ser feita pelo teste de $\chi^{2}$.

$$
\begin{aligned}
x^{2}=\sum_{i} \frac{\left(\mathrm{f}_{i}-\mathrm{nP}_{\mathrm{i}}\right)^{2}}{\mathrm{nP}_{\mathrm{i}}}=0,2904 & +1,1144+0,2342+ \\
& +0,1622 \\
x^{2} & =1,8012 \quad .
\end{aligned}
$$

Com 2 graus de liberdade, tem-se:

$$
\mathrm{P}\left[\mathrm{x}^{2} \geq 1,8012\right]=0,5937 .
$$

Tem-se, então, que os dados se ajustam à distribuição de. Poisson.

A seguir, verificou-se, atravēs do teste de qui-quadrado, que os dados de precipitação da Tabela 3 não podem ser enquadrados numa das distribuições do tipo exponencial selecionadas nesse trabalho.

De acordo com a Tabela 24, para a distribuição normal com parâmetros estimados $\widehat{m}=78,44$ e $s=23,161653$, obteve-se

$$
P\left[x^{2} \geq 15,597710\right]=0,0004 \quad(2 \text { g.1. }),
$$


50.

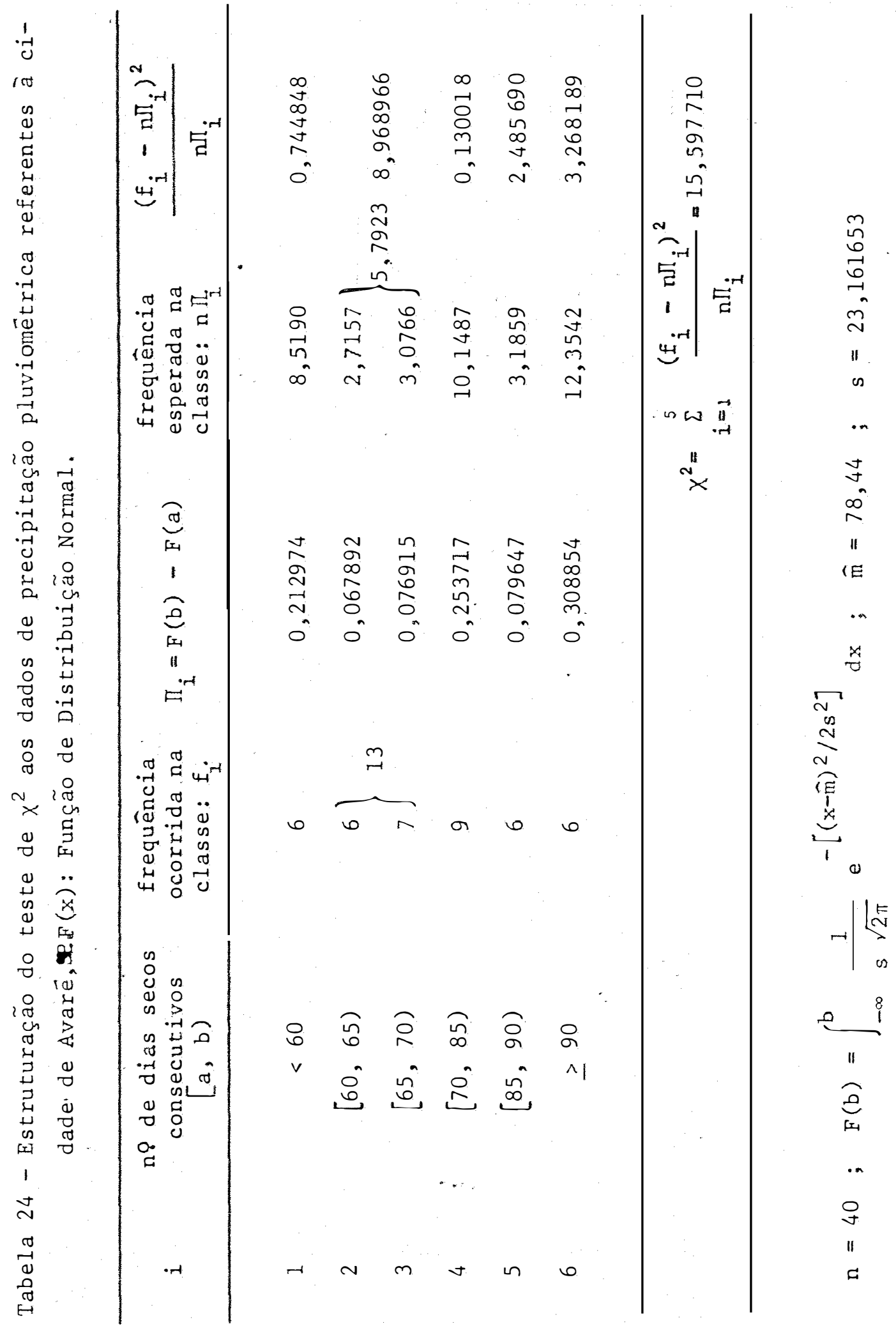


e de acordo com a Tabela 25, para a distribuição lognormal com parâmetros estimados $\hat{\mathrm{m}}=4,326446 \mathrm{e} s=0,263295$, obteve-se

$$
P\left[x^{2} \geq 9,164959\right]=0,0102 \quad(2 \text { g.1.) } .
$$

Aplicando-se a esses dados a função de distribuição de Gumbel, com parāmetros estimados $\hat{\alpha}=0,055370$ e $\hat{u}=68,0151272$, es timou-se, para o ano (civil), a precipitação máxima provável para o período de um dia e a probabilidade dessa estimativa não ser ultrapassada. Os resultados obtidos encontram-se na Tabela 26.

A compatibilidade dos dados com a distribuição de Gum bel pode ser feita pelo teste de $x^{2}$.

De acordo com a Tabela 27 , com 2 graus de liberade, obteve-se:

$$
\mathrm{P}\left[\mathrm{X}^{2} \geq 10,120347\right]=0,0063 .
$$

Pelo teste de qui-quadrado, os dados em estudo não aderem à distribuição de Gumbel com parâmetros estimados $\hat{a}=0,055370$ e $\hat{U}=68,015272$. 


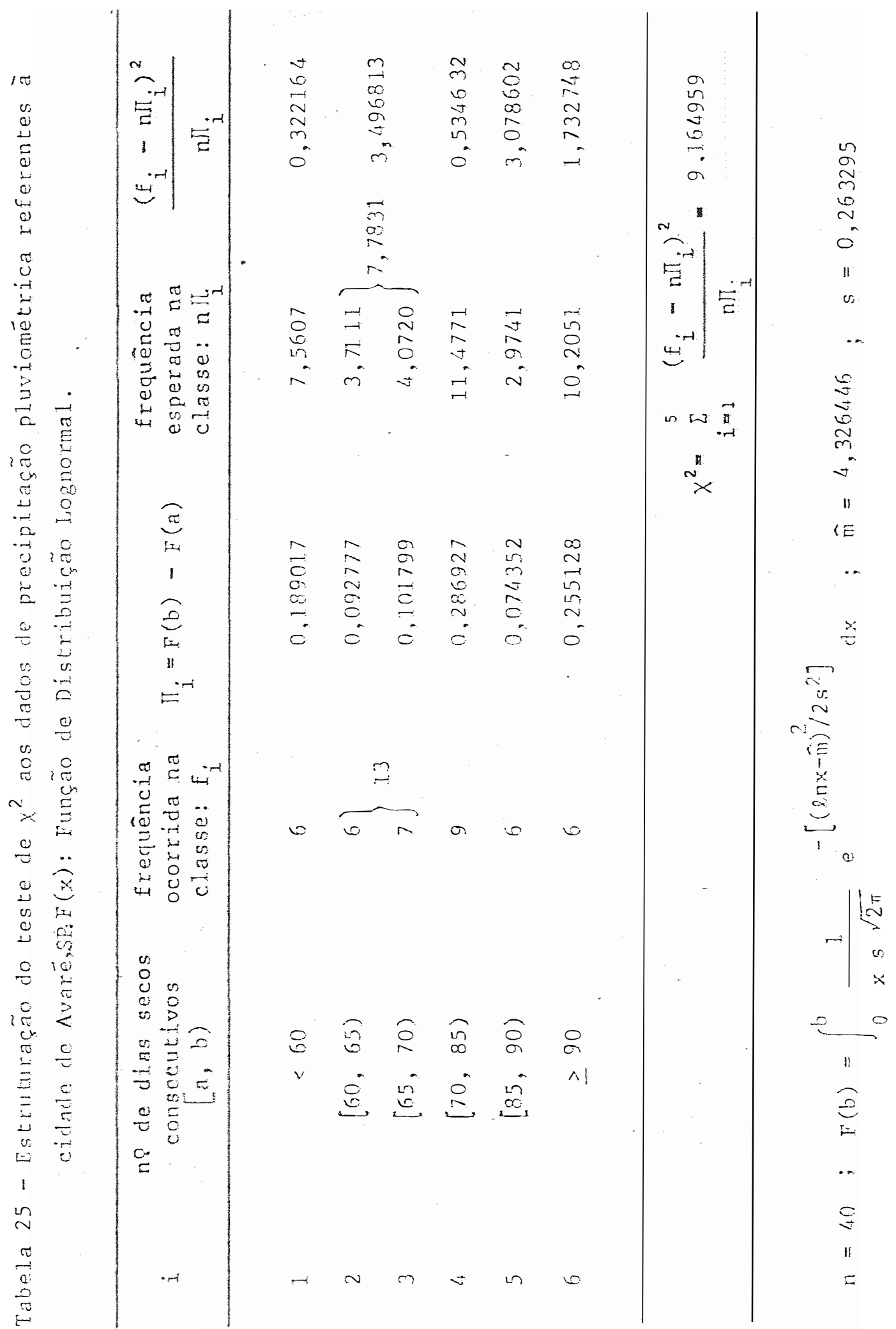


53.

Tabela 26 - Estimativas da precipitação mäxima provável no periodo de um dia, e a probabilicade dessas estimativas näo serem ultrapassadas, para a cidade de Avaré, SP.

Estimativas da precipitação Probabilidade das estimativas máxima provável (m) não serem ultrapassadas

$\begin{array}{ll}151,1 & 0,99 \\ 138,5 & 0,98 \\ 125,8 & 0,96 \\ 121,7 & 0,95 \\ 108,7 & 0,90 \\ 9.5,1 & 0,80 \\ 86,6 & 0,70 \\ 80,1 & 0,60 \\ 74,6 & 0,50 \\ 69,6 & 0,40 \\ 64,7 & 0,30 \\ 59,4 & 0,20 \\ 53,0 & 0,10\end{array}$




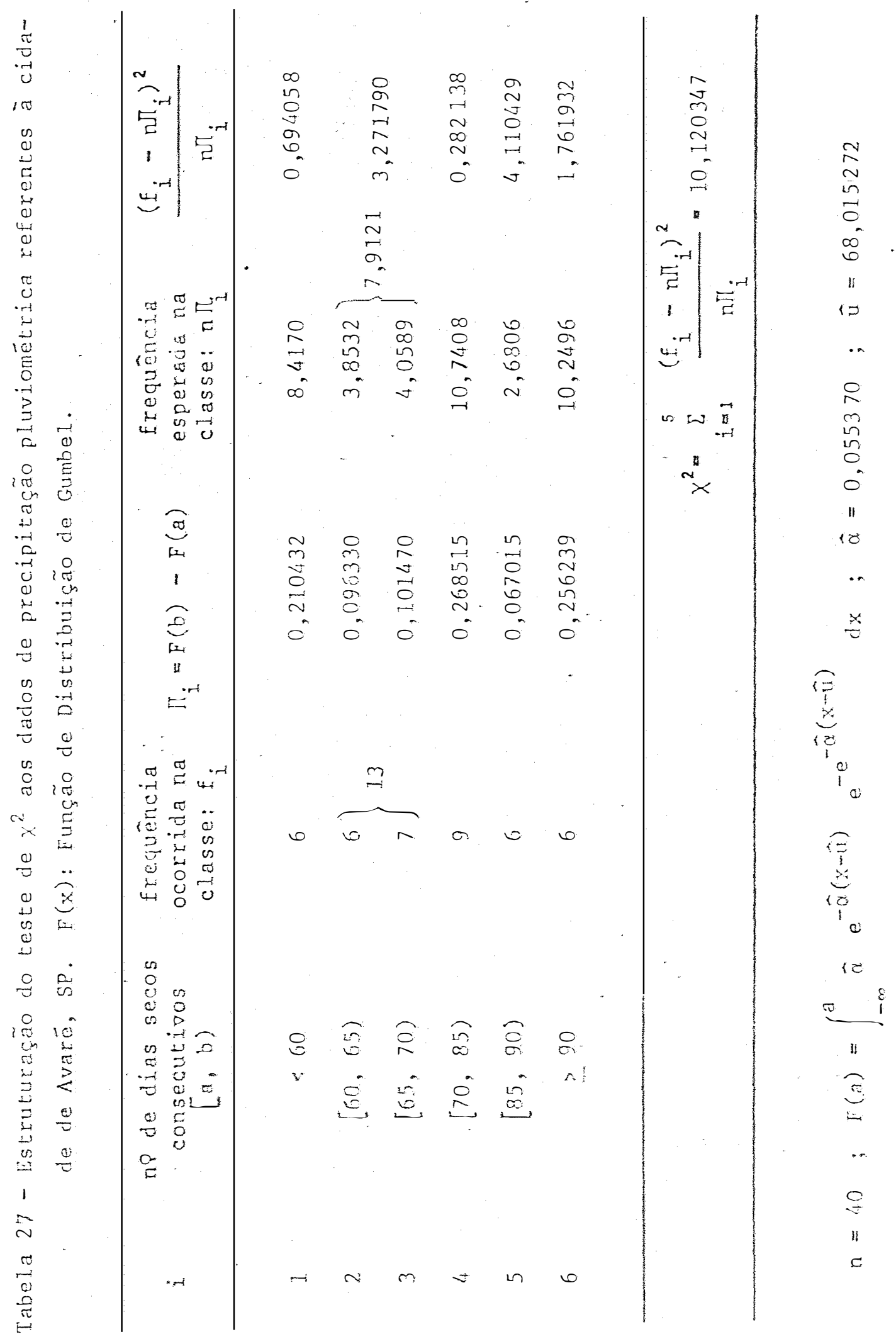


Nos 40 anos em estudo, acorrerem 138 aguaceiros de altura näo inferior a $50 \mathrm{~mm}$ (Tabela 4). Logo, a média anual é 3,45. Para o cálculo das probebilidades utilizou-se a distribuição de Poisson

$$
P[X=K]=e^{-3,45} \frac{(3,45)^{K}}{K !} \quad ; \quad K=0,1,2, \ldots
$$

Os resultados obtidos encontram-se na Tabela 28.

Tabela 28 - Ocorrência de aguaceiros de altura não inferior a $50 \mathrm{~mm}$ durante 40. anos (1942, 19.81), na cidade de Avaré, SP.

VALORES DA

VARIAVEL X
FREQUENCIA

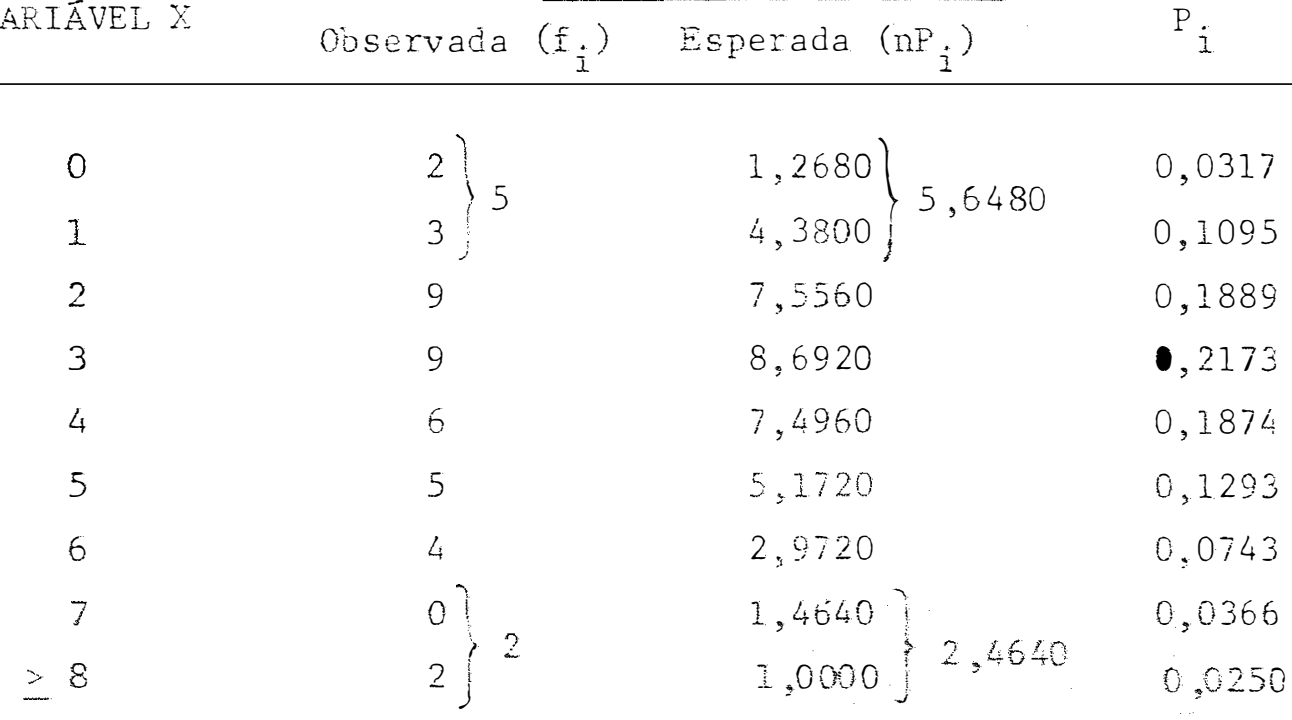

PROBABILIDADE

P. 
Da Tabela 28 tem-se que a probabilidade de que ocorra pelo menos um aguaceíro de altura excepcional durante o ano é estimada em $96,83 \%$,

$$
P[X \geq 1]=0,9683 .
$$

A verificação da compatibilidade dos dados com a dis tribuição de Poisson pode ser feita pelo teste de $x^{2}$.

$$
\begin{aligned}
x^{2}=\sum_{i} \frac{\left(f_{i}-\mathrm{nP}_{i}\right)^{2}}{\mathrm{nP}_{i}=0,0743+0,2760+0,0109+} \\
+0,2986+0,0057+0,3556+ \\
+0,08773 \\
x^{2}=1,1084 .
\end{aligned}
$$

Com 6 graus de liberdade, tem-se:

$$
\mathrm{P}\left[\mathrm{x}^{2} \geq 1,1084\right]=0,9535 .
$$

Tem-se, então, que os dados se ajustam à distribuição de Poisson.

Para a cidade de Itapeva, verificou-se, atravēs do teste de qui-quadrado $\left(x^{2}\right)$ ao nível de $5 \%$ de probabilidade, se é rạ zoâvel admitirque os dados de estiagens da Tabela 5 podem ser enquadrados numa das distribuições do tipo exponencial selecionadas nesse es tudo. 
De acordo com a Tabela 29, para a distribuição normal com parâmetros estimados $\hat{\mathrm{m}}=32,525$ e $\mathrm{s}=15,721922$, obteve-se:

$$
P\left[x^{2} \geq 7,644733\right]=0,0219 \quad(2 \mathrm{~g} .1 .)
$$

e de acorìo com a Tabela 30, para a distribuição lognormal com farâmetros estimados $\hat{\mathrm{m}}=3,386552$ e $\mathrm{s}=0,425357$, obteve-se:

$$
P\left[x^{2} \geq 4,318763\right]=0,115.4 \quad(2 \text { g.1.) } .
$$

Aplicando-se a função de distribuição de Gumbel com parâmetros estimaios $\bar{\alpha}=0,081570$ e $\widehat{v}=25,448639$ aos dados de estia gemi da Tabela 5, estimou-se a duração máxima provável (em nümero de dias secos consecutivos) da estiagem mais longa do ano (civil) e a probabiliciade dessa estimativâ não ser uitrapassada. Os resultados ob tidos encontram-se na Tabela 31.

A compatibilidade dos dados com a distribuiçäo de Gum bel pode ser fieita pelo teste de $x^{2}$.

De acordo com a Tabela 32 obteve-se:

$$
P\left[x^{2} \geq 3,962216\right]=0,131880 \quad(2 \mathrm{~g} \cdot 1 .) .
$$

Term-se, então, que os dados da Tabela 5 se ajustam à distribuição de Gumbel com parânetros estimados $\widehat{a}=0,081570 \mathrm{e}$ $\widehat{u}=25,44863$. 
58.

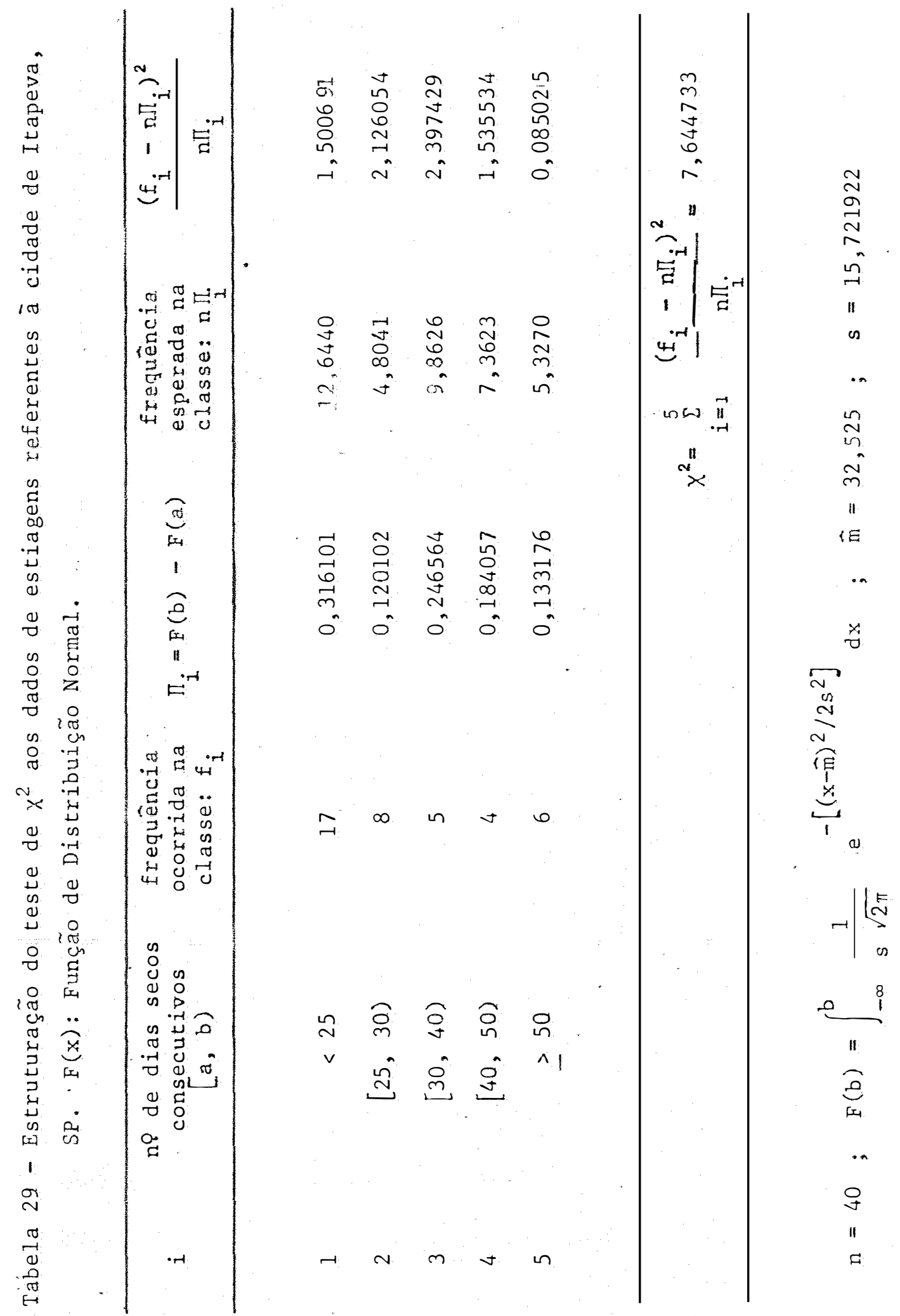




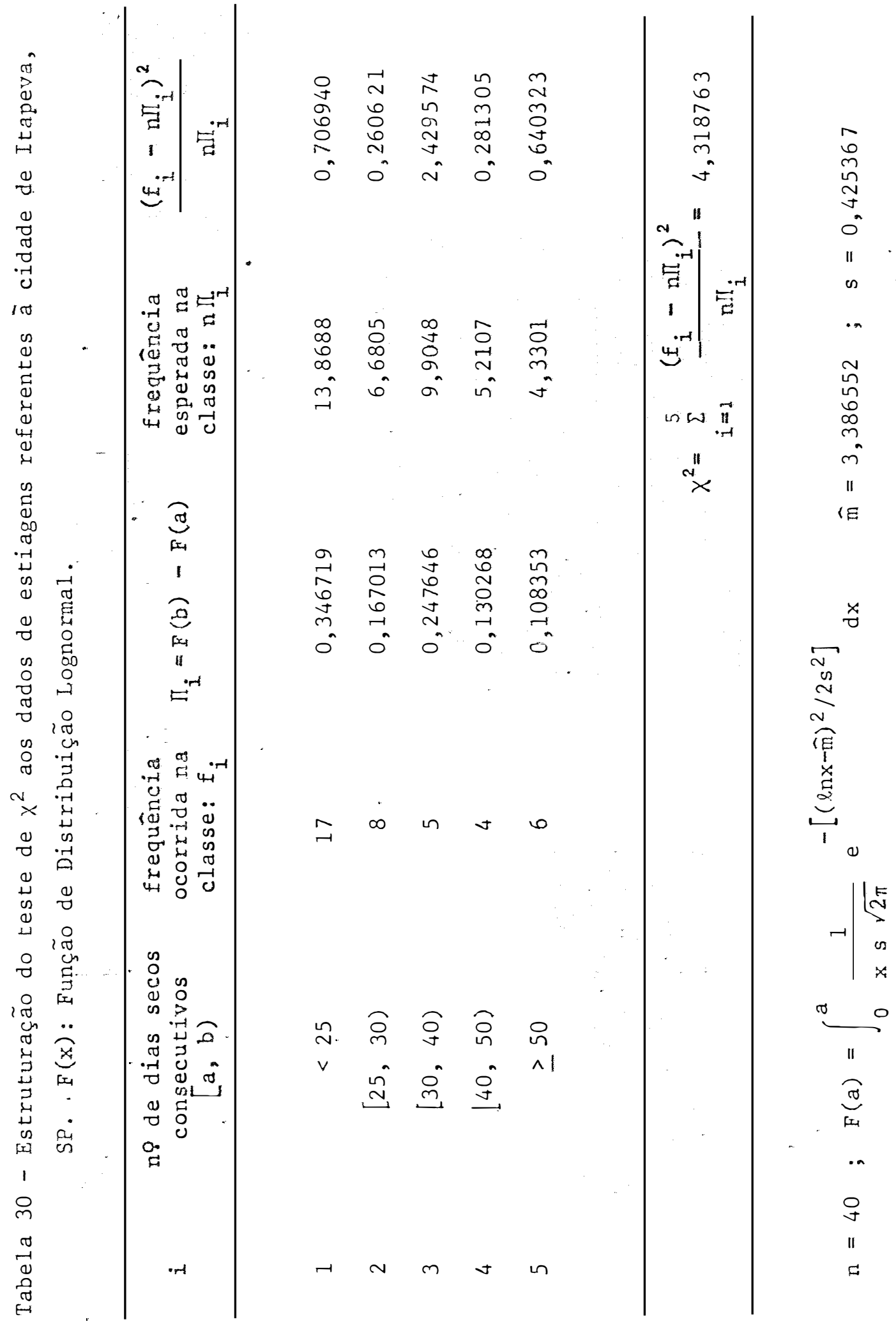


60.

Tabela 31 - Estimativas da duração máxima provável da estiagem mais longa do ano, em número de dias secos consecutivos, e a probabilidade dessas estimativas não serem ultrapassadas, para a cidade de Itapeva, SP.

\begin{tabular}{|c|c|}
\hline $\begin{array}{l}\text { Estimativas da duração } \\
\text { mäxima provāvel }\end{array}$ & $\begin{array}{c}\text { Probabilidade das estimativas } \\
\text { não serem ultrapassadas }\end{array}$ \\
\hline 82 & 0,99 \\
\hline 73 & 0,98 \\
\hline 65 & 0,96 \\
\hline 62 & 0,95 \\
\hline 53 & 0,90 \\
\hline 44 & 0,80 \\
\hline 38 & 0,70 \\
\hline 34 & 0,60 \\
\hline 30 & 0,50 \\
\hline 27 & 0,40 \\
\hline 23 & 0,30 \\
\hline 20 & 0,20 \\
\hline 15 & 0,10 \\
\hline
\end{tabular}


61.

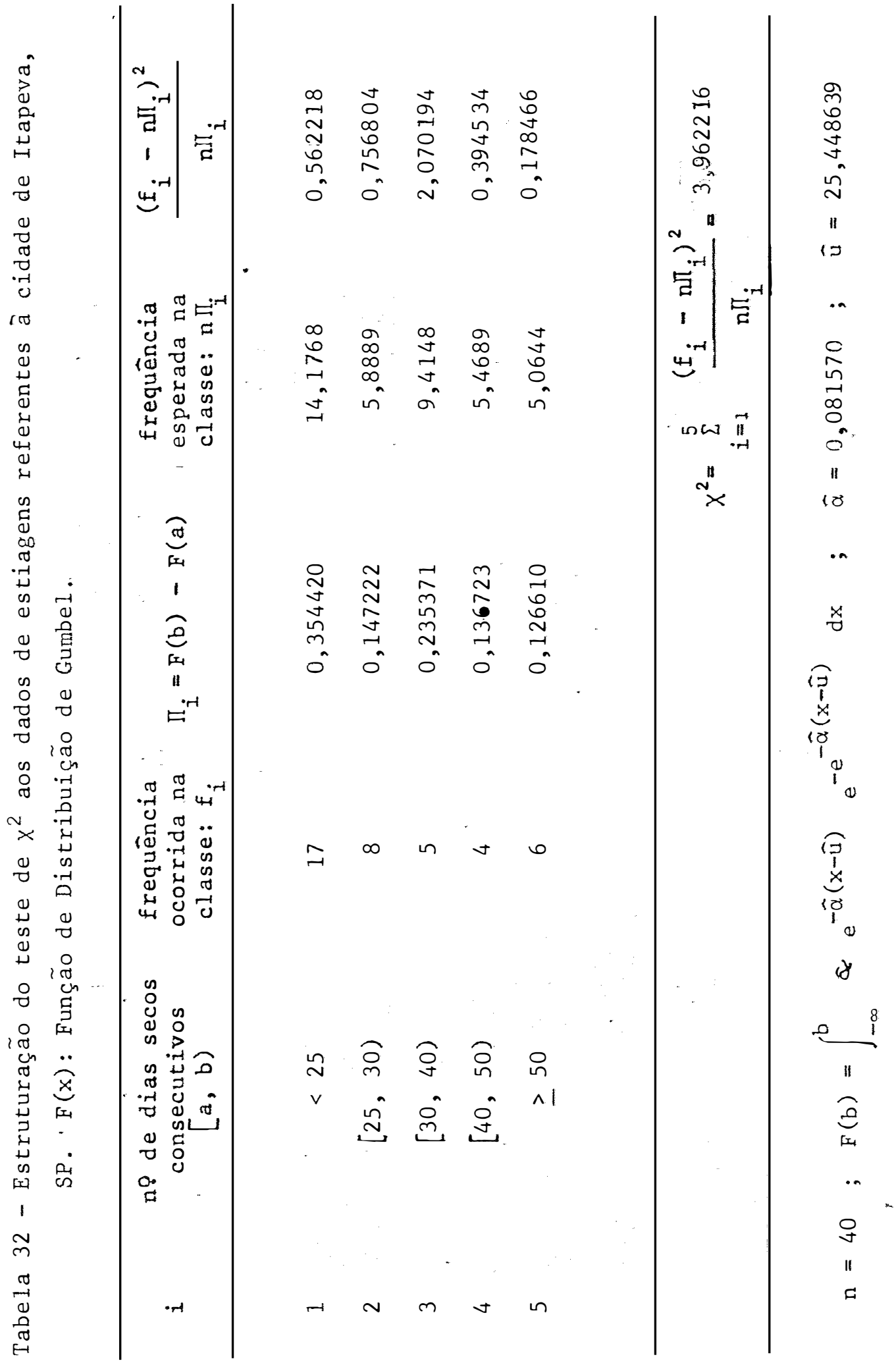


Nos 40 anos em estudo, ocorreram 20 estiagens de duração não inferior a 30 dias secos consecutivos (Tabela 6). Logo, a média anual é 0,5 .

Para o cälculo das probabilidades utilizou-se a distribuição de Poisson

$$
P[X=K]=e^{-0,5} \frac{(0,5)^{K}}{K !} \quad ; \quad K=0,1,2, \ldots
$$

Os resultados obtidos encontram-se na Tabela 33.

Tabela 33 - Ocorrência de estiagens de duração não inferior a 30 dias consecutivos durante 40 anos $(1942,1981)$, para a cidade de Itapeva, SP.

\begin{tabular}{|c|c|c|c|}
\hline \multirow{2}{*}{$\begin{array}{l}\text { VALORES DA } \\
\text { VARIĀVEL } X\end{array}$} & \multicolumn{2}{|c|}{ FREQUENCIA } & \multirow{2}{*}{$\begin{array}{c}\text { PROBABILIDADE } \\
\mathrm{P}_{i}\end{array}$} \\
\hline & Observada $\left(f_{i}\right)$ & Esperada $\left(\mathrm{nP}_{i}\right)$ & \\
\hline 0 & 26 & 24,2600 & 0,6065 \\
\hline 1 & 10 & 12,1320 & 0,3033 \\
\hline 2 & 3 & 3,0400 & 0,0760 \\
\hline 3 & $0\} 4$ & $0,5040\} 3,6080$ & 0,0126 \\
\hline$\geq 4$ & 1 & $a, 064 a J$ & 0,0016 \\
\hline
\end{tabular}

Da Tabela 33 tem-se que a probabilidade de que não ocorra nenhuma estiagem de duração não inferior a 30 dias secos consecutivos durante ó ano é estimada em 60,65\%

$$
P[X=0]=0,6065 .
$$


Teni-se, tanibém, que

$$
\begin{gathered}
p[X \leq 1]=0,9098 \\
\text { A verificaça da compatibilidade dos dados com a dis }
\end{gathered}
$$

tribuição de Pcissor pode ser feita pelo teste de $x^{2}$.

$$
\begin{aligned}
x^{2}=\sum_{i} \frac{\left( \pm_{i}-n P_{i}\right)^{2}}{n P_{i}} & =0,1248+0,3747+0,0426 \\
x^{2} & =0,5421 .
\end{aligned}
$$

Com 1 grau de liberdade, ten-se:

$$
P\left[y^{2} \geq 0,5421\right]=0,4616 .
$$

Ten-se, entä́o, que os cados se ajustan à cistribuição de Poisson.

Foi verificado, através do tesce de qui-cuadrado, que os dados de prectptaça da Tabela 5 poden sez encuidrabos numa das Gistribuicöes do tipo exponencial selecionadas nesse trabalho.

De ecordo con a Tabela 34, para a distribuicão nomal con parânetros estimados $\overline{\text { in }}=72,7 \mathrm{e}=18,139375$, obteve-se:

$$
P\left[X^{2} \geq 3,000768\right]=0,2230 \quad(2 g .1 .)
$$

e de acordo com a Tabela 35, pare a distibuicáo logromà con parame tros estimados $\overline{\mathrm{x}}=4,258208 \mathrm{e}=0,237381$, oveve-se:

$$
\mathrm{P}\left[x^{2} \geq 1.914882\right]=0,3838 \quad(2 \mathrm{~s} \cdot 1 .) .
$$


64.

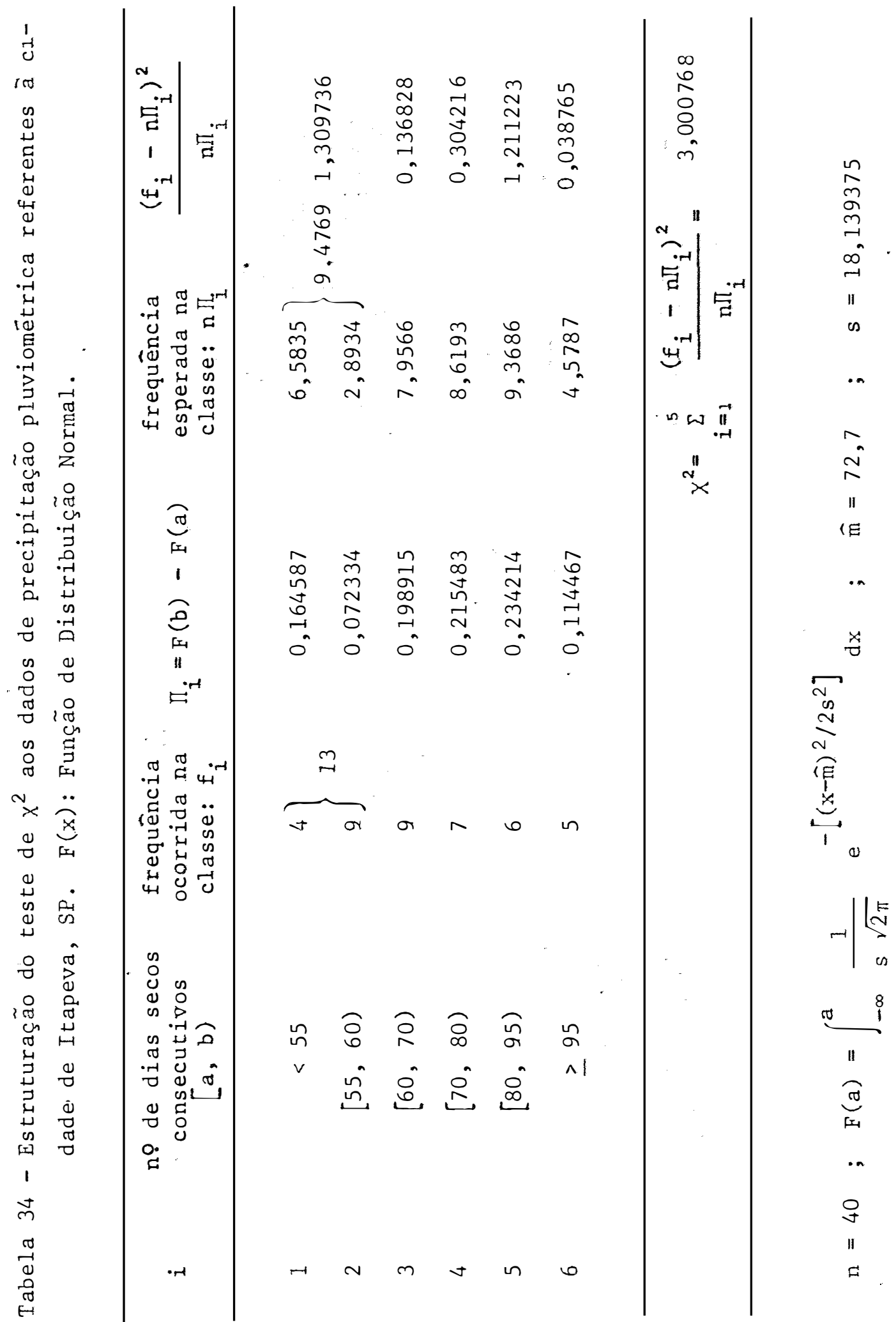


65.

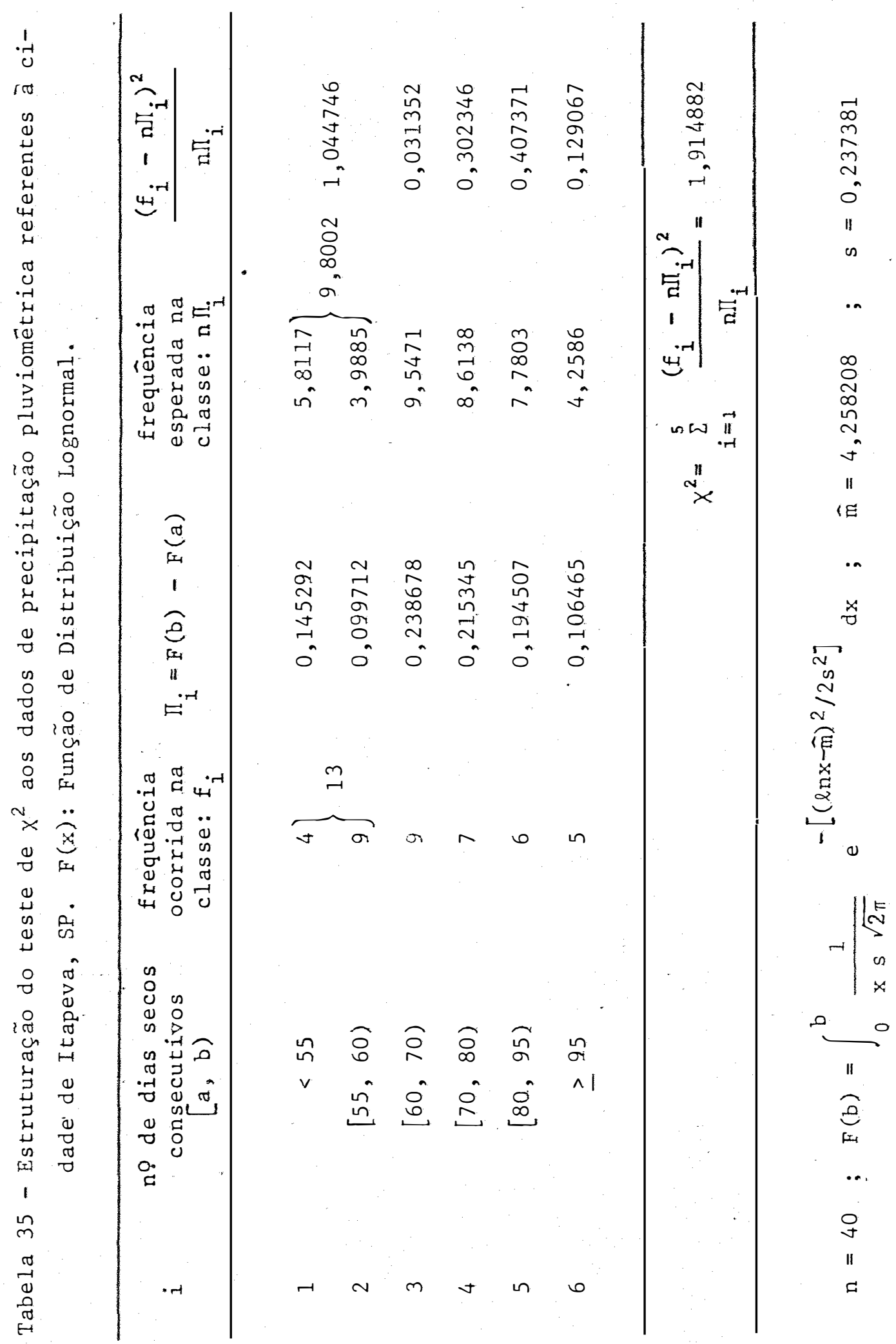


Os resultados obtidos através da Tabela 35 permitem afirmar que, de acordo com o teste de qui-quadrado, os dados de precipitação da Tabela 5 se ajustam à distribuição lognormal.

Aplicando-se a esses dados a função de distribuição de Gumbe1, com parâmetros estimados $\widehat{\alpha}=0,070699$ e $\hat{\mathrm{u}}=64,535556$, es timou-se, para o ano (civi1), a precipitação mäxima provāve1 para o período de um dia e a probabilidade dessa estimativa não ser ultrapassada. Os resultados obtidos encontram-se na Tabela 36.

A compatibilidade dos dados com a distribuição de Gum bel pode ser feita pelo teste de $x^{2}$.

De acordo com a Tabela 37, obteve-se:

$$
\mathrm{P}\left[\mathrm{x}^{2} \geq 1,429165\right]=0,4894 \quad(2 \mathrm{~g} \cdot 1 .) .
$$

Segundo o teste de qui-quadrado, os dados em estudo aderem à distribuição de Gumbel com parâmetros estimados $\widehat{\alpha}=0,070699$ e $\widehat{u}=64,535556$. 
67.

Tabela 36 - Estimativas da precipitação máxima provável no período de um dia, e â probabilidade dessas estimativas não serem ultrapassadas, para a cidade de Itapeva, SP.

Estimativas da precipitação Probabilidade das estimativas máxima provāvel (mm) não serem ultrapassadas

$\begin{array}{ll}129,6 & 0,99 \\ 119,7 & 0,98 \\ 109,8 & 0,96 \\ 106,5 & 0,95 \\ 96,4 & 0,90 \\ 85,8 & 0,80 \\ 79,1 & 0,70 \\ 74,0 & 0,60 \\ 69,7 & 0,50 \\ 65,8 & 0,40 \\ 61,9 & 0,30 \\ 57,8 & 0,20 \\ 52,7 & 0,10\end{array}$


68.

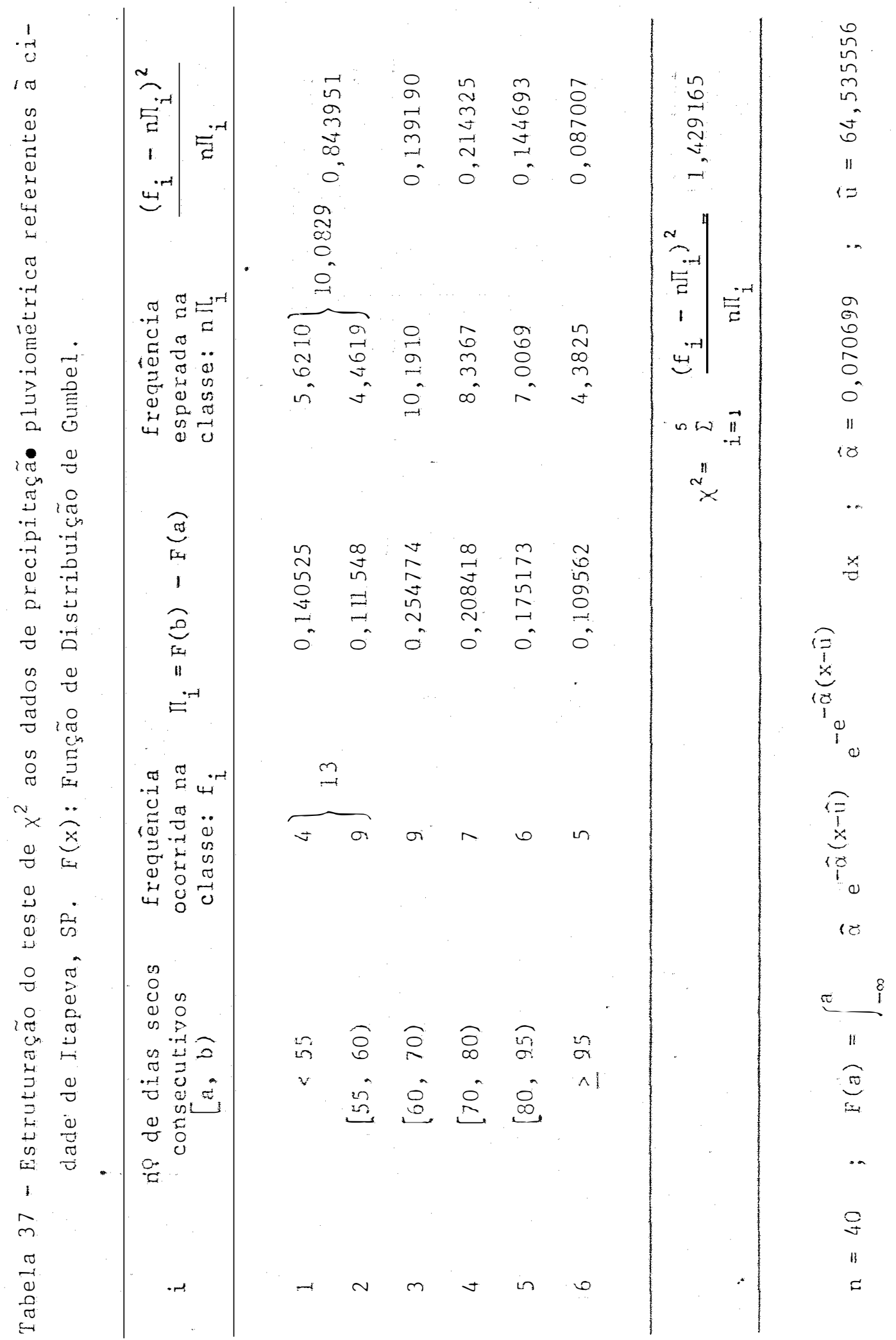


Nos 40 anos em estudo, ocorreram 99 aguaceiros de al tura não inferior a 50 mo (Tabela 6). Logo, a média anual é 2,475.

Para o célculo das probabilićades utilizou-se a diserỉbuição de Poisson

$$
\mathrm{I}[\mathrm{X}=\mathrm{K}]=\mathrm{e}^{-2,4+75} \frac{2,475^{\mathrm{k}}}{\mathrm{K} !} \quad ; \quad \mathrm{k}=0,1,2, \ldots
$$

Os resultados obtiàos encontram-se na Tabela 38.

Tabela 38 - ocorrência de aguaceiros de altura não inferior a $50 \mathrm{~mm}$ durante 40 anos (1942, 1981), na cidade de Itapeva, SP.

\begin{tabular}{|c|c|c|c|c|c|}
\hline \multirow{2}{*}{$\begin{array}{l}\text { WALORES DA } \\
\text { VARIAVEI Y }\end{array}$} & \multicolumn{4}{|c|}{ EREOUENCIL } & \multirow{2}{*}{$\begin{array}{c}\text { PFOEABILIDADE } \\
P_{i}\end{array}$} \\
\hline & Observade & $e\left(f_{i}\right)$ & Esperada & $\left.P_{i}\right)$ & \\
\hline 0 & 2 & & 1,7160 & & 0,0429 \\
\hline 1 & 12 & & 5,4000 & & 0,1350 \\
\hline 2 & 11 & & $\varepsilon, 5040$ & & 0,2126 \\
\hline 3. & 3 & & 8,928 & & 0,2232 \\
\hline 4 & 7 & & 3,0320 & & 0,1758 \\
\hline 5 & 3 & & 4,4320 & & 0,1108 \\
\hline$\epsilon$ & 1 & 5 & 2,3240 & 8,42 & 0.0581 \\
\hline$\geq 7$ & 11 & & 1,6640 & & 0,04316 \\
\hline
\end{tabular}

Da Tabela $3 \varepsilon$ tem-se que a probabilidade de que ocorra pelo menos um aguaceiro de altura não inferior a $50 \mathrm{~mm}$ é estimada em 0,9571, ou 95,71\%. 
A verificação da compatibilidade dos dados com a dis tribuição de Poisson pode ser feita pelo teste de $x^{2}$.

$$
\begin{aligned}
x^{2}=\sum_{i} \frac{\left(f_{i}-n P_{i}\right)^{2}}{n P_{i}}=0,0470 & +8,0667+0,7326+3,9361+ \\
& +0,0001+1,3891 \\
x^{2}=14,1716 &
\end{aligned}
$$

Com 4 graus de Iibercade tem-se:

$$
P\left[X^{2} \geq 14,1716\right]=0,0068 .
$$

Tem-se, então, que os dados em estucio ñăo se ajustam à distribuição de Poisson.

\section{7 - Sugestões parâ Pesquisas Posteriores}

Com base nos resuliados obtidos no presente estudo,e com o fim de esclarecer certas dúvidas, prezende-se:

a) Verificar a validaùe da seguinte nipotese: Se ce dados de tre

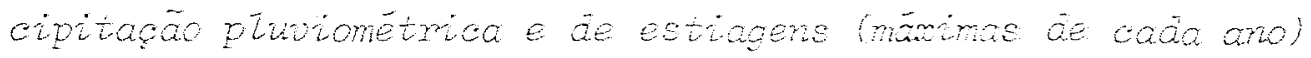
para séries com mais de 30 mos podem ser ajustacias a fungäo

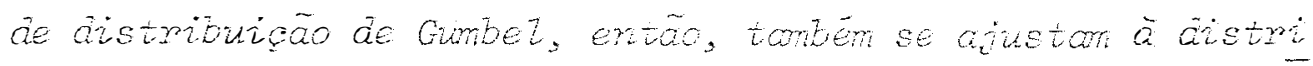
burgão tognomat, que é do tipe emponenctat. 
b) Realizar um estudo com as diversas funções de distribuição do tipo exponencial, a fim de se deduzir uma, tal que a recíproca da hi pötese (a) seja verdadeira.

c) Verificar se a ocorrência de estiagens com duração não inferior a $20,40,50$ e 60 dias secos consecutivos podem ser estudados pe Ia distribuição de Poisson.

Para isso, pretende-se levantar dados das diversas es tações meteorológicas do Estado de São Paulo. 
5. CONCLUSOES

5.1 - A estimativa da duração mäxima provável da estiagem mais lon ga do ano, com probabilidade de $95 \%$ dessa estimativa não ser ultrapassada, para a cidade de Presidente Prudente, é de 78 dias secos consecutivos.

5.2 - A probabilidade de que não ocorram durante o ano estiagens com duração não inferior a 30 dias secos consecutivos, na ci dade de Presidente Prudente, é estimada em 34,99\%, e a probabilidade de que ocorra no máximo uma é estimada em 71,73\%.

5.3 - Os dados correspondentes à ocorrência de aguaceiros ajustam à função de distribuição de Poisson, de acordo com o teste de $x^{2}$ para a cidade de Presidente Prudente. 
5.4 - Na cidade de Avaré, a estimativa da duração máxima provável da estiagem mais longa do ano, com probabilidade de $95 \%$ des sa estimativa não ser ultrapassada, é de 74 dias secos consecutivos.

5.5 - Na cidade de Avaré, a probabilidade de que ocorra durante o ano no máximo uma estiagem com duração não inferior a 30 dias secos consecutivos, é estimada em $83,54 \%$, e a probabilidade de que não ocorra nenhuma é estimada em 48,43\%.

5.6 - Durante o ano, a probabilidade de que ocorra na cidade de Avaré pelo menos um aguaceiro de altura $\mathrm{h} \geq 50 \mathrm{~mm}$, é esti mada em 96,83\%, e a probabilidade de que não ocorra é estimada em $3,17 \%$.

5.7 - Nas cidades de Avaré e Presidente Prudente, os dados de pre cipitação pluviométrica obtidos, divididos em classes de fre quência, não se ajustam à distribuição de Gumbel, de acordo com o teste de $x^{2}$, ao nível de $5 \%$ de probabilidade.

5.8 - Na cidade de Itapeva, a estimativa da duração máxima provável da estiagem mais longa do ano, com probabilidade de $95 \%$ dessa estimativa não ser superada, é de 62 dias secos conse cutivos.

5.9 - A probabilidade de que na cidade de Itapeva ocorra no mäximo uma estiagem de duração não inferior a 30 òias secos con secutiros é estimada em $90,98 \%$. 
5.10 - Durante o uno: a estimativa da precipitaço márime provável, no perjodo de un dia, con probabiziaje je $95 \%$ dessa estimativa näo ser ultrapassada, é de 06,5 mo para a cidace de Itapeva.

5.11 - Na cidade de Itapeva, os dados corresponjentes à ocorrência de aguaceiros de altura excencional não se ajustaram à função de distribufica de Poisson, de acordo com o teste de $x^{2}$, ao nivel de $5 \%$ de probabiliciade.

5.12 - A função de distribujeão do tipo exponencial, indicada para os dados de estiagens e precipitações pluviométricas má ximas de cada ano) é a função de distribuição lognomal.

5.13 - No presente estudo, verificou-se que, se os daùos obtidos se ajustam à função de distribuição de Gymbel, então se ajustam à função de listribuição lognormal.

5.14 - No presente estudo, verificourse que os dados referentes a estiagens se ajustan ben à fução de distribuiço de cum bel. 
75.

6. LITERATURA CITAOA

BhNARTO, D.A., 1973. Estimativa cas Precipitacões Máximas Prováveis no Estaco de São Paulo. Jaboticubal, UNESP. 119 p. (Tese de Doutoramento).

BHAT, U.N., 1972, Elements of ApDied Stochastic Processes. Jonn Wiley, Nove York. $415 \mathrm{p}$.

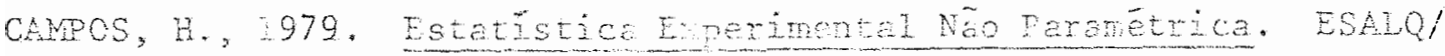
USF. Piracicaba. $343 \mathrm{p}$.

CHow, V.T., 2964. Handwook of Appljed Hedrology. MoGraw-Hil Book, Nova York. $1453 \mathrm{p}$.

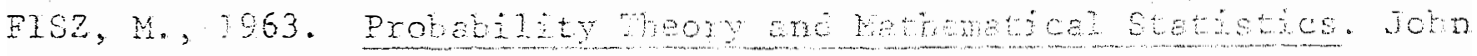
Wiley: Nove York. 677 f.

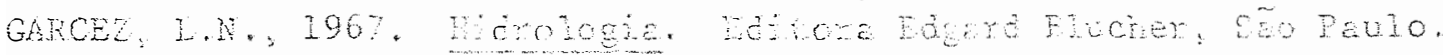
$249 p$ 
GNentwo, B.V., 1978. The Theory of Proberticy. Mir Publishers, Moscou. $392 \mathrm{p}$.

GUEEL, E.J., 1941. The return period of Elons. Ann. Math. Statistics. Baltimote, 12: 163-190.

HOEL, P.G.; S.C. PORT e C.J. STONE, 1978. Introducão à Teorie da. Probabilidade. Editora Interciencia, Rio de Janeiro. $269 \mathrm{p}$.

KRISHAM, A. e R.S. KUSHWAHA, 3978. Comparison of Gumbel and Jenkinson's Methods of Estimating Probable Maximum Rainfall Intensities Over India for Different Return Feriods. Journal of the Indian Geophysical Union. (s.1.), 4 : 50-70.

OCCHIFINTI, A.G. e D.M. SANTOS, 1965. Anéise cas Mexinas Intensidades de Chuva na Cjòade de São Paulo. Instituto Astronónico e Geofísico da USP, São Paulo. 41 p.

SILVA, M.M. E. S.V. Assis, 1979. Probabilidades de ocorrencia de Estiagem no triângulo Mineiro e sua influência na cultura do mi 1ho. Boletim da Socierade Brasileira de Peteorologia. 2: 43-56.

SCOTON, L.C. E V.F. da CRU2, 1966. Ocorrencie de aguaceiros de altu re excepcional em Piracicaba. D.A.E. Sä́ Faulo, 62: 3-10. 